University of Denver

Digital Commons @ DU

$11-1-2011$

\title{
The Relationship Between Adolescents' Stage of Change and Their Ability to Establish a Working Alliance in Psychotherapy
}

Jennifer Lynn Grote

University of Denver

Follow this and additional works at: https://digitalcommons.du.edu/etd

Part of the Psychology Commons

\section{Recommended Citation}

Grote, Jennifer Lynn, "The Relationship Between Adolescents' Stage of Change and Their Ability to Establish a Working Alliance in Psychotherapy" (2011). Electronic Theses and Dissertations. 250. https://digitalcommons.du.edu/etd/250

This Dissertation is brought to you for free and open access by the Graduate Studies at Digital Commons @ DU. It has been accepted for inclusion in Electronic Theses and Dissertations by an authorized administrator of Digital Commons@DU. For more information, please contact jennifer.cox@du.edu,dig-commons@du.edu. 
THE RELATIONSHIP BETWEEN ADOLESCENTS' STAGE OF CHANGE AND THEIR ABILITY TO ESTABLISH A WORKING ALLIANCE

\title{
IN PSYCHOTHERAPY
}

\author{
A Dissertation \\ Presented to \\ The Faculty of the Morgridge College of Education \\ University of Denver \\ In Partial Fulfillment \\ of the Requirements for the Degree \\ Doctor of Philosophy \\ By \\ Jennifer Lynn Grote \\ November 2011 \\ Advisor: Maria T. Riva, Ph.D
}


Author: Jennifer L. Grote

Title: THE RELATIONSHIP BETWEEN ADOLESCENTS' STAGE OF CHANGE AND THEIR ABILITY TO ESTABLISH A WORKING ALLIANCE IN PSYCHOTHERAPY

Advisor: Maria T. Riva, Ph.D

Degree Date: November 2011

\section{ABSTRACT}

This study examined the process of psychotherapy with adolescents in group psychotherapy, assessing the adolescents' motivation to change behaviors, also called stage of change beliefs, and how these relate to the quality of the relationship, or working alliance, between the adolescent and therapist. Adolescent ratings of group cohesiveness were also measured. Twenty participants between the ages of 13 and 18 receiving group treatment in an Intensive Outpatient Program (IOP) at a psychiatric hospital in Colorado were included in the study. The IOP group targeted parents and adolescents and implemented a manualized treatment to improve family communication and adolescent functioning. The group met for five weeks with three sessions per week. Assessment measures utilized included the Ohio Scales, the University of Rhode Island Change Assessment (URICA), the Working Alliance Inventory-Short Form Revised (WAI-SR), and the Group Climate Questionnaire-Short (GCQ-S). Participants completed the WAISR and GCQ-S four times to measure working alliance development and group cohesion. The URICA was administered at the beginning and end of the IOP group to measure the participants' stage of change beliefs. Data were analyzed with profile analyses, independent sample t-tests, and Pearson product moment correlations. Participants improved in overall functioning with decreased problem severity ratings during the group. Working alliance and group cohesion were shown to be correlated during the 
second half of the IOP group. Working alliance and stage of change beliefs were not correlated. Working alliance ratings did not increase significantly over time. Parent and adolescent ratings of the adolescents' stage of change beliefs at the beginning and end of the IOP group were not correlated. Adolescents with previous mental health treatment rated their stage of change as Precontemplation most often while those with no prior mental health treatment rated stage of change as Preparation or Action. Overall, these findings suggest that brief group treatment may improve adolescent functioning and decrease their ratings of problem severity. Also significant for adolescent group psychotherapy research is the relatedness of working alliance and group cohesion. Further research is needed to learn how stages of change beliefs affect adolescents and how the working alliance develops in psychotherapy. 
Table of Contents

Chapter 1-Introduction 1

Social and Clinical Implication $\quad 4$

$\begin{array}{ll}\text { Status of the Literature } & 7\end{array}$

Working Alliance $\quad 8$

$\begin{array}{lr}\text { Group Cohesion } & 10\end{array}$

$\begin{array}{ll}\text { Stage of Change Beliefs } & 10\end{array}$

$\begin{array}{ll}\text { Justification for the Study } & 12\end{array}$

Hypotheses and Research Questions $\quad 15$

$\begin{array}{ll}\text { Definition of Terms } & 15\end{array}$

Chapter 2-Review of the Literature 18

$\begin{array}{ll}\text { Working Alliance } & 20\end{array}$

Developing Working Alliance in Psychotherapy 23

Developing Working Alliance with Children and Adolescents 25

Working Alliance and Outcome with Children and Adolescents 27

Measuring Working Alliance 29

$\begin{array}{ll}\text { Group Cohesion } & 32\end{array}$

Developing Group Cohesion with Children and Adolescents 33

Measuring Group Cohesion 34

The Transtheoretical Model of Change 36

$\begin{array}{ll}\text { Stages of Change } & 37\end{array}$

Measuring Stages of Change $\quad 39$

Working Alliance and Stages of Change 41

Chapter Summary 45

Chapter 3-Methodology 46

$\begin{array}{ll}\text { Participants } & 46\end{array}$

Adolescent Demographic Information $\quad 47$

Parent Demographic Information $\quad 48$

Inclusion and Exclusion Criteria $\quad 50$

$\begin{array}{ll}\text { Instruments } & 51\end{array}$

Working Alliance-Short Form Revised 51

Group Climate Questionnaire-Short Form $\quad 52$

University of Rhode Island Change Assessment 53

Demographic Questionnaires $\quad 55$

The Ohio Scales $\quad 55$

$\begin{array}{ll}\text { Procedure } & 56\end{array}$ 
Description of Outpatient Clinic 56

Informed Consent $\quad 57$

Difficulty Recruiting Participants $\quad 59$

Data Collection $\quad 60$

Data Analyses $\quad 61$

$\begin{array}{ll}\text { Chapter Summary } & 65\end{array}$

Chapter 4-Results $\quad 66$

Preliminary Analyses $\quad 66$

Reliability of Measures $\quad 66$

Analysis of Missing Data $\quad 67$

Completed Participants Compared to Dropout Participants 68

Mean Comparisons by Gender $\quad 70$

$\begin{array}{ll}\text { Primary Analyses } & 71\end{array}$

Statistical Analyses Addressing Hypotheses $\quad 71$

Hypothesis $1 \quad 71$

$\begin{array}{ll}\text { Hypothesis } 2 & 74\end{array}$

Hypothesis $3 \quad 75$

Hypothesis $4 \quad 77$

Statistical Analyses Addressing Research Questions 79

$\begin{array}{ll}\text { Research Question } 1 & 79\end{array}$

Research Question $2 \quad 80$

$\begin{array}{ll}\text { Supplemental Analyses } & 81\end{array}$

Differences in the Ohio Scales over Time $\quad 81$

GCQ-S (Engaged) Scores and WAI-SR Total Scores 82

Impact of Previous Mental Health Treatment on Stage of Change 84

$\begin{array}{ll}\text { Chapter Summary } & 85\end{array}$

Chapter 5-Discussion $\quad 87$

Specific Findings and Implications $\quad 88$

Efficacy of Brief Treatment for Adolescents 90

Relationship between Working Alliance and Group Cohesion 90

Development of Working Alliance over Time 92

Stage of Change Beliefs over Time 93

Relationship between Working Alliance and Stages of Change 94

Limitations of the Study 96

$\begin{array}{lr}\text { Recommendations for Future Research } & 100\end{array}$

$\begin{array}{ll}\text { Conclusions } & 103\end{array}$ 
$\begin{array}{ll}\text { Appendices } & 118\end{array}$

$\begin{array}{llr}\text { Appendix A Invitation Flyer } & 119\end{array}$

$\begin{array}{lll}\text { Appendix B Informed Consent (Parent) } & 121\end{array}$

Assent Form (Adolescent) 123

$\begin{array}{lll}\text { Appendix C Demographic Questionnaire (Parent) } & 125\end{array}$

Demographic Questionnaire (Adolescent) 126

Appendix D Working Alliance Inventory-Short Form Revised 128

University of Rhode Island Change Assessments $\quad 129$

Group Climate Questionnaire-S (GCQ-S) 135

Appendix E Institutional Review Board Approval Letter 137 


\section{List of Tables}

Table 1 Overview of Adolescent Demographic Characteristics for the 25 Individuals who Consented to the Study Including Study Dropouts and the 20 Study Completers

Table 2 Overview of Parent Demographic Characteristics

Table 3 Hypotheses and Research Questions for the Study

Table 4 Means and Standard Deviations for Dropout Participants and Study Completers on Main Assessment Measures

Table 5 Descriptive Statistics for Male and Female Participants' WAI-SR Total scores for Session 1, Session 4, Session 7, and Session 15

Table 6 Main Effects of Time, Gender, and Gender by Time Interaction for WAISR Total Scores for Session 1, Session 4, Session 7, and Session 15

Table 7 Pearson Product-Moment Correlations between WAI-SR Subscale Scores and URICA at Session One

Table 8 Pearson Product-Moment Correlations between WAI-SR Subscale Scores and URICA at Session Fifteen

Table 9 Descriptive Statistics for Male and Female Participants GCQ-S (Engaged) Subscale for Session 1, Session 4, Session 7, and Session 15

Table $10 \quad$ Main Effects for Time and Gender and Gender by Time Interaction for GCQ-S

Table 11 Pearson Product-Moment Correlations between GCQ-S (Engaged) scores and WAI-SR Total Scores at Session One, Four, Seven, and Fifteen 
List of Graphs

Figure 1 Profile Analysis of WAI-SR Total Scores by Gender for Sessions One, Four, Seven, and Fifteen

Figure 2 Profile Analysis of GCQ-S (Engaged) Subscale Scores by Gender from Sessions One to Fifteen 


\section{Chapter 1}

\section{INTRODUCTION}

One in five adolescents experience significant symptoms of emotional distress and one in ten are emotionally impaired (Surgeon General's Report on Mental Health, 2008). However, only about $10 \%$ of children and adolescents with symptoms of mental health problems receive any mental health evaluation or service (Kataoka et al., 2002). These statistics demonstrate a need for increased mental health services for children and adolescents. In order to provide quality services for this population it is important to understand both effective treatment interventions and the most efficacious means of engaging children and adolescents in psychotherapy. It is not enough to simply replicate research with adults in child and adolescent populations or apply successful adult interventions to treatment with children and adolescents. More research is needed with children and adolescents to understand the specific variables contributing to process and outcome in psychotherapy.

Examining the process of psychotherapy includes exploring the relationship between the client and therapist. For children and adolescents this relationship can manifest in many ways, as this population receives mental health services in a variety of settings, including schools, hospitals, community mental health centers, and clinics. There is also variability in the modality of service provided, including individual therapy, 
group therapy, school-based therapy, day treatment, or inpatient psychiatric hospitalization. Despite the setting or modality, the therapeutic relationship has been found to be an important variable affecting both process and outcome in psychotherapy (Martin, Garske, \& Davis, 2000; Munder, Wilmers, Leonhart, Linster, \& Barth, 2009).

Research has been conducted on the therapeutic relationship with adults in psychotherapy but few studies have investigated the therapeutic relationship in child psychotherapy. In a 2003 meta-analysis of child psychotherapy research, Shirk and Karver found 23 studies investigating the therapeutic relationship compared to Horvath and Bedi's (2002) report of over 2000 studies with adults. For child and adolescent individual therapy, Shirk and Karver (2003) found the therapeutic relationship's association to psychotherapy outcome to be essentially identical to similar adult research. With children and adolescents who participate in group psychotherapy, the therapeutic relationship is affected by the relationships between the group members and the therapist as well as the relationships between the group members. Research on group therapy with children and adolescents is “...in its infancy" (Shechtman, 2001, p. 293) compared to adult group therapy research. However, group therapy for children and adolescents has been shown to be effective compared to control groups (Hoag \& Burlingame, 1997). The multiple therapeutic relationships that exist in a group setting present unique challenges when considering the variables impacting the process and outcome in group psychotherapy. Children and adolescents with their challenging needs may pose additional hurdles for both research and intervention with this population. 
Research has found psychotherapy to be effective for adults but the existing literature does not show that psychotherapy is as effective for children and adolescents (DiGuiseppe, Linscott, \& Jilton, 1996). Several possible reasons may exist to explain why therapy with children and adolescents is challenging. First, children and adolescents have long been viewed as difficult to engage in therapy (Church, 1994; DiGuiseppe et al., 1996). Also, children and adolescents referred for psychotherapy typically do not initiate treatment (Kazdin \& Weisz, 1998). For this reason, children and adolescents who engage in psychotherapy often have difficulty forming a bond with their therapist, acknowledging or agreeing on the stated "problem" for which they were referred, and implementing recommended interventions (Shirk \& Karver, 2003). They are often brought to therapy by their parents or caregivers and given the impression that they are the "identified patient" or viewed as the person responsible for the issues in the family.

There are clear differences between children and adolescents and adult psychotherapy clients, and it seems apparent that children and adolescents have different needs in psychotherapy than adults. Much of the prevailing psychotherapy research has attempted to apply theory and principles effective with adults to interventions with children and adolescents, with mixed results. Additionally, the difficulties that children and adolescents encounter in psychotherapy coupled with high attrition rates and poor outcomes indicate a need to determine the relationship variables that most influence this population's success in psychotherapy. In an attempt to further the existing psychotherapy research with children and adolescents, this study was designed to gather information about the process of psychotherapy with adolescents in group psychotherapy, 
including the adolescents' beliefs and expectations about psychotherapy and how these relate to the quality of the relationship between the adolescent client and therapist and the adolescent's ratings of the group as a whole.

This chapter begins with an overview of the social and clinical implications of the difficulties children and adolescents face in psychotherapy, including high dropout rates and difficulty developing an effective therapeutic relationship. Next, a review of the existing process and outcome psychotherapy literature with children and adolescents is discussed. This is followed by the justification for the study. The hypotheses, research questions, and definitions of terms are described to explain the course of the study. Finally, a brief summary concludes this chapter.

\section{Social and Clinical Implications}

There is an increasing need for understanding the components of successful intervention with children and adolescents. They begin treatment at greater rates than in the past but consistently produce higher attrition rates than adults (Kazdin, 1997). Spirito et al. (2011) reported the average length of treatment for outpatient adolescent clients in urban clinics is three to four visits, with only $9 \%$ of clients still attending after three months. Kazdin (1996) concurred with this finding, stating 40-60\% of children and adolescents drop out prematurely from services, or before mental health providers believe treatment to be concluded. Reasons for attrition from treatment vary but research has found that ethnicity, residing in a single-family household, low socio-economic status, and low parent ratings of adolescent functioning are significant risk factors (Warnick, Gonzalez, Weersing, Scahill, \& Woolston, 2011). 
The consequence of dropping out of treatment for children, adolescents, and their families involves more than failing to benefit from much-needed psychotherapy services. In a study with children referred for antisocial behavior, Kazdin (1990) found that premature termination from treatment resulted in children exhibiting more severe delinquent behaviors and caused greater stress for the parent or caregiver than those who stayed in treatment. There are implications for mental health providers as well, since attrition from therapy decreases the likelihood that those who need care will receive it. Attrition is also linked with cancelled appointments and no-shows that can result in decreased productivity for the providers (Kazdin, 1996).

Many community mental health centers, schools, agencies, and hospitals have looked for ways to increase mental health providers' productivity, affect change with more individuals, and be more cost-effective overall. Thus, group psychotherapy has been increasingly utilized with children, adolescents, and adults across many settings and has been shown to be successful and cost-effective as a means of providing psychotherapy (Submission for the Surgeon General's Report, 1998). Hoag and Burlingame's 1997 meta-analysis of group psychotherapy with children found group therapy to be an effective means of intervention with this population, with the average child in group therapy functioning better than $73 \%$ of those in control groups. Group therapy has also been shown to be especially well suited to meet the developmental needs of adolescents, when a major psychological task lies in establishing their individual identities and separating from parental figures (Kymissis, 1996). 
Regardless of the type of psychotherapy provided, the high dropout rates for children and adolescents highlight the need to identify the factors that are considered barriers to treatment. Clinical barriers to treatment may be a perception that treatment is irrelevant to the client's problems, or a poor relationship with the therapist (Garcia \& Weisz, 2002; Kazdin, Holland, \& Crowley, 1997). Clinicians have identified the therapeutic relationship as highly important when working with children and adolescents and relate the quality of the relationship to outcome in psychotherapy (Bickman et al., 2000; Kazdin, Siegel, \& Bass, 1990). Children and adolescents' expectations about psychotherapy and their ability to have insight about their stated "problem" behavior or motivation to change may impact their ability to establish a relationship with their therapist (DiGuiseppe et al., 1996).

The lack of connectedness between adult and children and adolescent psychotherapy research has significant social and clinical implications that affect children, adolescents, their families, and mental health providers. A better understanding of the therapeutic relationship and how children and adolescents' expectations about psychotherapy contribute to the therapeutic relationship is needed. Further research in this area may offer critical implications for clinical interventions aimed at tailoring psychotherapy to meet the needs of children and adolescents. Improved intervention and techniques may impact psychotherapy outcome and decrease attrition rates for this population. 


\section{Status of the Literature}

This study focuses on the impact of two separate psychotherapy constructs with adolescents in group psychotherapy while also considering the impact of group cohesion on these variables. These constructs are the therapeutic relationship or working alliance between the client and therapist, and the clients' understanding of their stated "problem" and motivation or readiness to change. There is a small body of literature examining the relationship variables necessary for psychotherapy with children and adolescents to produce positive outcomes and their readiness to change "problem" behaviors in psychotherapy.

Evidence in adult psychotherapy research suggests a strong working alliance is crucial to the therapeutic process and also may contribute to client satisfaction and treatment progress (Eltz, Shirk, \& Sarlin, 1995; Horvath \& Symonds, 1991). In fact, studies have shown that with adult clients alliance accounts for an average effect size of .22 (Martin, Garske, \& Davis, 2000). In contrast to adult psychotherapy literature, few empirical studies specifically address the relationship variables necessary to effectively engage adolescents in psychotherapy (Diamond, Liddle, Hogue, \& Dakof, 1999; Oetzel \& Scherer, 2003; Shirk \& Saiz, 1992). Karver et al. (2008) found correlations between the therapeutic alliance and increased client involvement with depressed adolescents in psychotherapy. Additionally, improved client responsiveness to treatment was correlated with positive ratings of the therapeutic bond for motivated adolescent clients (Smith \& Grawe, 2003). Motivation to change has been shown to be a needed component in facilitating lasting behavior changes (Prochaska, Norcross, \& DiClemente, 1992). Two 
recent studies, Fitzpatrick and Irannejad (2008) and Emmerling and Whelton (2008), examined the impact of a client's stage of change beliefs, or motivation to change behaviors, at the outset of psychotherapy on the development of working alliance.

Fitzpatrick and Irannejad (2008) investigated adolescents' stage of change beliefs at the beginning of psychotherapy and measured the development of the working alliance across the course of treatment. These researchers found adolescents who were less motivated to change their behaviors had poorer ratings of working alliance than those who had more insight into their problem behaviors and willingness to change. Similarly, Emmerling and Whelton (2008) found that adult clients who demonstrated movement from a lower stage of change to a higher stage reported stronger working alliances over those who did not demonstrate stage of change movement. However, researchers caution against applying the adult psychotherapy findings on working alliance to child and adolescent populations (Fitzpatrick \& Irannejad, 2008). More research is needed to determine how the working alliance develops with children and adolescents as well as other important factors contributing to successful psychotherapy outcomes.

Working Alliance. Relationship variables can also be termed "common factors" and refer to the common elements of therapy that contribute to outcomes. In 1936, Rosenweig proposed that psychotherapy had certain necessary components regardless of the theoretical approach employed (Wampold, 2001). Since that time, psychotherapy literature has focused on these common factors in an attempt to tease out the necessary components of psychotherapy to better predict outcome and influence the change process. One of these common factors is the working alliance, or the collaborative bond between 
the therapist and client (Horvath, 2001). Early psychoanalytic theorists first described the working alliance in connection to the transference neuroses that the client struggled with as they attempted to work on his or her therapy goals (Horvath \& Symonds, 1991). The working alliance was later defined as a separate construct that existed as an essential component to successful psychotherapy (Horvath \& Greenberg, 1986). Bordin's (1979) theory of the working alliance as a pan-theoretical construct divided the working alliance into three parts; goals, tasks, and bond. Bordin hypothesized that these components all contributed to the development of the working alliance.

DiGiuseppe et al. (1996) suggested traditional child and adolescent psychotherapy models overly focus on the bond, or working alliance, to facilitate change. These models ignore the goals and task aspects of the working alliance, which may be more important when working with adolescents. Clinicians often fail to recognize crucial differences between adolescent and adult populations, particularly the adolescents' desire for autonomy and their interest in being agents of their own change (Church, 1994). This search for autonomy during adolescence is a normative developmental process in which the adolescent and parent attempt to redefine the parent-child relationship (DiGiuseppe et al., 1996). This involves the adolescent separating from the parent to establish individuality while maintaining close emotional ties for support.

Diamond et al. (1999) suggested an effective working alliance with adolescents promotes a sense of self-competence and self-efficacy needed to facilitate change. In this vein, group psychotherapy may be useful so that adolescents can work to build alliance and engagement to a peer group, shifting dependency from parents to peers. Group 
psychotherapy can provide an avenue to foster ego development, learn social skills and eventually achieve constructive independent functioning (Kymissis, 1998).

Group Cohesion. In group psychotherapy research the concepts of working alliance and group cohesion have been utilized somewhat interchangeably. In group psychotherapy, group cohesion has been defined as the basic bond between an individual member and the group as a whole, the other group members, the psychotherapist, and the therapeutic work (Piper, Marraches, Lacroix, Richardson, \& Jones, 1983). Budman, Soldz, Demby, Feldstein, Springer, and Davis (1983) described the working alliance in groups as the bond between group members and their collective struggle to achieve common goals. These authors defined group cohesion as the bond between the members of the group.

Some researchers have cautioned against using the concepts working alliance and group cohesion interchangeably to define group phenomena. Marziali, Monroe-Blum, and McCleary (1997) found that working alliance explained additional variance beyond that explained by group cohesion, demonstrating the importance of investigating the bond between the group member and psychotherapist (working alliance) separately from the bond between the group members (group cohesion). Van Andel, Erdman, Karsdorp, Appels, and Trijsburg (2003) concurred with this finding in that group cohesion and working alliance represented different relationships in group psychotherapy and contributed in different ways to therapy outcome.

Stage of Change Beliefs. In order to better understand the impact of working alliance on therapy outcome, the client's expectations for therapy must be addressed. 
Since children and adolescents are not typically self-referred for therapy, they may have misguided or ill-informed ideas about psychotherapy. Therapists must be careful to define and address each client's needs because children and adolescents have different needs than adults in psychotherapy. This population may present as unmotivated or refuse to work on treatment goals (Greenstein, Franklin, \& McGuffin, 1999). It is critically important for the therapist to address client expectations at the outset of therapy and discuss informed consent, confidentiality, and the specific parameters of the therapy relationship. Research has suggested that determining the clients' motivation for change in therapy and the extent to which they can identify a problem behavior may be important in the development of the working alliance (Derisley \& Reynolds, 2000).

In adult psychotherapy literature, the client's motivation for change and the process of change in psychotherapy has been researched using the Transtheoretical Model (Prochaska \& DiClemente, 1982). The Transtheoretical Model is an integrative model of behavioral change that encompasses the individuals' decision-making process and how they attempt to modify or change behaviors over time. The underpinnings of the model suggest that regardless of the treatment modality or intervention utilized the client progresses through five discrete stages of change in attempts to modify or change behavior.

The client's stage of change beliefs have been shown to be a crucial factor in predicting therapeutic change with adult populations. The Transtheoretical Model initially proposed four stages of change, including Precontemplation, Contemplation, Action, and Maintenance (McConnaughy, Prochaska, \& Velicer, 1983). A fifth stage, 
Preparation, was added later to address the stage in which the client is committed to act and believes in the ability to change (Prochaska, Norcross, \& DiClemente, 1994). In the earliest stage, Precontemplation, the client may not be fully aware of the problem behavior and may not be motivated to change in the near future. In the Contemplation stage, clients are aware of the problem behavior but have not decided to take steps to actively change their behavior. The Preparation stage is categorized by the clients' attempts to make a specific plan for change and take some initial steps toward modifying their behavior. In the Action stage, the clients alter their behavior in an effort to change the identified problem. The final stage, Maintenance, is viewed as the stage in which clients prevent relapse and continue striving toward maintaining the changes they have made. The Stages of Change and the Transtheoretical Model (Prochaska \& DiClemente, 1982) were originally designed for individual psychotherapy interventions but have been more widely utilized in research focusing on substance abuse, behavioral interventions, and health psychology. Most of this research has been conducted with adult populations and has indicated that the stages of change have the ability to predict outcome in therapy (Derisley \& Reynolds, 2000).

\section{Justification for the Study}

While there is limited research on children and adolescents' readiness to change, studies have found adolescents who scored in the Contemplation or Action range on the University of Rhode Island Change Assessment (URICA) had higher ratings of the working alliance than those who had Precontemplation scores and that adolescents were more likely to be in the Precontemplation stage if they were uncommitted to change or 
did not have a clear plan (Cohen, Glaser, Calhoun, Bradshaw, \& Pertrocelli, 2005;

Fitzpatrick \& Irannejad, 2008). Additionally, the individual's readiness for change has been shown to affect the formation of the working alliance (Henry \& Strupp, 1994). Linking the constructs of working alliance and readiness to change with adolescent psychotherapy clients may provide insight into how to best engage this population.

In a review of the literature on the psychotherapy relationship with children and adolescents and the factors that contribute to this populations' understanding of "problem" behavior and their readiness to change, it seems clear that more research is needed to better understand this population. Kazdin et al. (2006) reported that psychotherapy research with children and adolescents had fewer numbers of empirical studies and less precise methodology than adult research. Meanwhile, premature termination from therapy continues to be a significant problem for children, adolescents, and their families. Having a better understanding of the variables that influence psychotherapy may allow therapists to serve this population more effectively, decrease attrition rates, and predict outcomes in psychotherapy. In the future, understanding these important variables will allow for tailored interventions to best meet the needs of children and adolescents.

One purpose of this study was to address some of the gaps in research with adolescents utilizing the constructs of working alliance and stage of change within group psychotherapy. Researchers have cautioned against generalizing working alliance research with adults to interventions with children and adolescents given their different treatment needs and cognitive capabilities (DiGuiseppe et al., 1996). This study focused 
on the development of the alliance between the therapist and adolescent in a group psychotherapy intervention. The concept of group cohesion was investigated to determine how this variable impacted the process and outcome of psychotherapy. Strong working alliances and positive group cohesion ratings have been shown to be important in predicting psychotherapy retention, adherence to goals, and implementation of interventions in both individual and group psychotherapy (Diamond et al., 1999; Horvath \& Bedi, 2002; Robbins, Mayorga, Mitrani, et al., 2006, Van Andel et al., 2003).

Another reason for conducting this study was to integrate two concepts that have not been widely studied with adolescents, the working alliance and readiness to change, also called stage of change beliefs. Also, this study allows for better understanding the components of the working alliance with adolescents and how their stage of change beliefs impacts the development of the therapeutic relationship. While the constructs of working alliance and stage of change beliefs have been shown to impact the process of change in psychotherapy, there are few studies that link the two constructs together and investigate their influence on psychotherapy. Research to date has shown the working alliance greatly impacts the psychotherapy relationship and has also shown the benefits of applying the Transtheoretical Model to psychotherapy interventions (Derisley \& Reynolds, 2002; Emmerling \& Whelton, 2008, Fitzpatrick \& Irannejad, 2008). A final reason for conducting this study was to further psychotherapy research with children and adolescents. This oft-misunderstood and overlooked population is in need of effective mental health services geared to their specific needs. 


\section{Hypotheses and Research Questions}

This study addressed four hypotheses and two research questions. The first hypothesis predicted that the adolescent sample would rate the working alliance more positively over time. It was also predicted that the adolescent samples' URICA subscale scores would progress to a higher stage than at the outset of psychotherapy, such as movement from Precontemplation to Contemplation. Third, it was hypothesized that there would be a relationship between URICA subscale scores and WAI-SR total score and subscales scores in the adolescent sample. Fourth, it was hypothesized that the participants' group cohesion ratings would improve over time as the group progressed from session one to fifteen. The research questions for this study included determining whether there was a relationship between the parents' stage of change beliefs about their adolescents' problem behavior and their adolescents' stage of change beliefs at session one and measured again at session fifteen.

Definition of Terms in the Study

Family Therapy. An intervention that consists of client, one or more family members, or caregivers, and therapist. Family therapy targets issues that are impeding the functioning of the family (Corey \& Corey, 2006).

Individual Therapy. A dyadic intervention between therapist and client (Lambert, 2005). Group Climate Questionnaire-Short Form (GCQ-S). An assessment tool for groups meant to assess levels of group cohesion, engagement, and avoidance. The measure was developed by McKenzie (1983) and has three forms: self-rating, therapist rating and observer rating. 
Group Therapy. An intervention consisting of one or more group leaders and 3 or more group members (Corey \& Corey, 2006).

Stages of Change. The central component of the Transtheoretical Model and the stages an individual must progress through as behavior is changed (Prochaska, \& DiClemente, 1982).

1. Precontemplation: The first stage of change in which the individual is unaware of the "problem" behavior or has no motivation to change the behavior.

2. Contemplation: The second stage of change in which the individual is aware the "problem" behavior exists but has made no steps to change.

3. Preparation: The third stage of change in which the individual attempts to make a specific plan for change and take some initial steps toward modifying their behavior.

4. Action: The fourth stage of change in which the individual alters their behavior in an effort to change the "problem" behavior.

5. Maintenance: The final stage of change in which the individual continues the progress made and attempts to avoid relapse.

Transtheoretical Model. Developed by Prochaska and DiClemente (1982) as an integrative model of behavioral change that encompasses the individual's decisionmaking process and how they attempt to modify or change behaviors over time. University of Rhode Island Change Assessment (URICA). An assessment tool developed by McConnaughy, DiClemente, Prochaska, and Velicer (1983) that measures an 
individual's readiness to change. The measure provides a profile of scores on four subscales, precontemplation, contemplation, action, and maintenance. The Transtheoretical Model and the stages of change were later proposed to include the stage of preparation as well.

Working alliance. First described by early psychoanalytic theorists, the term was coined by Greenson (1965) to describe the agreement between the client seeking change and the therapist willing to act as a facilitator of change.

Working Alliance Inventory-Short Form (WAI-SR). An assessment tool developed by Hatcher and Gillaspy (2006) as a short version of the WAI (Horvath \& Greenberg, 1986).

Chapter two focuses on the relevant literature related to working alliance and stages of change with adolescent clients in group psychotherapy. The existing literature is described in detail and the need for further research is highlighted. Additionally, the relevant assessment measures for working alliance, stages of change, and group cohesion are described. 


\section{Chapter 2}

\section{LITERATURE REVIEW}

Children and adolescents are in need of mental health services, but little is known about the effectiveness of individual psychotherapy with this population (Shirk \& Karver, 2003). Group psychotherapy with children has been shown to be effective when compared to control groups but Hoag and Burlingame (1997) concluded that more research was needed to better inform clinical practice. Group therapy is an accepted modality of treatment for adolescents and allows for increased social interaction in a nonthreatening environment (Shechtman, 2001) and the ability to develop peer relationships. The current study gathered information about the process of psychotherapy with adolescents in a group setting, examining the relationship variables that impact therapy. Among these variables are the working alliance and the adolescent clients' readiness to change. Understanding the specific relationship variables that contribute to treatment with this population are important social and clinical issues. Increasing numbers of children and adolescents are in need of psychotherapy yet attrition is high for this population (Kazdin, 1996).

To determine the level of need for child and adolescent mental health services in the United States as well as specific barriers contributing to attrition, a study called the Methods for the Epidemiology of Child and Adolescent Mental Disorders (MECA) was conducted. This study investigated over 1,200 parent/child dyads' use of mental health 
services and found $17.1 \%$ of the study's participants demonstrated an unmet need for mental health services (Goodman et al., 1998; Cornelius, Pringle, Jernigan, Kirisci, \& Clark, 2001). In addition to unmet need, these and other researchers have identified certain socio-demographic and clinical barriers to treatment including ethnicity, income, severity of the child's symptoms, parent psychopathology, parental fear of the child being removed from the home or social service involvement, and parental stress (Cornelius et al., 2001; Spirito et al., 2011; Warnick et al., 2011). These barriers also contribute to higher attrition rates, the consequences of which are severe as these populations may fail to benefit from much-needed interventions. Further research in this area may offer implications for clinical interventions aimed at tailoring psychotherapy to better meet the needs of this population.

This chapter focuses on research devoted to defining and studying the construct of the working alliance and its importance in psychotherapy. The working alliance has theoretical roots in the transference and attachment relationship between the therapist and client. It also has been shown to be a robust variable in predicting psychotherapy outcomes (Horvath \& Greenburg, 1986; Martin, Garske, \& Davis, 2000). The next section presents an overview of the research on the working alliance with children and adolescents and how the alliance affects psychotherapy outcomes. The current study focuses on adolescents in a group psychotherapy intervention, thus the concept of group cohesion is defined and parallels are drawn between working alliance and group cohesion. Cohesion is an important component of group therapy in order for work and change to occur (Yalom \& Leszcz, 2005). Following this is a discussion of how the 
working alliance and group cohesion develop in groups and how this contributes to outcome in psychotherapy.

The client's readiness to change, or stage of change beliefs also have been shown to contribute to outcome in psychotherapy. The client's stage of change beliefs have been outlined by Prochaska and DiClemente (1982) as an important construct within the Transtheoretical Model. This model is defined and described in this chapter. Readiness to change has been linked to client behavior and motivation to participate in psychotherapy and has been shown to be important in the development of the working alliance. Client readiness to change and working alliance have been widely researched in adult psychotherapy literature but few studies link the two concepts to psychotherapy with adolescents. The limited research in this area and the need for further investigation are highlighted.

\section{Working Alliance}

Research on psychotherapy outcomes over the last several decades has pointed to the concept that different types of therapies produce similar levels of therapeutic change (Luborsky, Singer, \& Luborsky, 1975; Martin et al., 2000; Smith \& Glass, 1977). This has resulted in a trend toward uncovering the factors common to all therapies that may affect change. These "common factors" are thought to be used across various theoretical orientations to facilitate change. Common factors can be defined as “...variables that are found in a variety of therapies regardless of the therapist's theoretical orientation" (Lambert, 2005, p. 97). Research suggests that these "common factors" may include empathy, genuineness, and rapport building on the part of the therapist. These factors 
have been shown to predict attrition and therapy retention rates as well as outcomes in psychotherapy with adults, children, and adolescents. The level of the client's psychological distress, the strength of the working alliance, and the client's readiness to change has also been shown to affect psychotherapy outcomes. These "common factors" are an important focus of research because they have been shown to decrease attrition rates and predict therapeutic change.

The working alliance or therapeutic alliance has been identified as one of the "common factors" in psychotherapy. The terms working alliance, therapeutic alliance, and helping alliance may be utilized interchangeably, but for the purposes of this review the term working alliance will be used. Freud (1912) was one of the first theorists to explore the relationship between the client's attachment to the analyst as well as the client's positive feelings toward the analyst. He believed this positive component of the relationship represented a partnership against the client's neuroses and had its roots in the client's transference relationship (Horvath \& Symonds, 1991). Freud believed the attachment relationship between the therapist and the patient's ego was a vital component for creating change. Greenson (1965) added to Freud's theory when he described the patient's difficulty to engage in a stable working relationship with the therapist. He maintained that a difference existed between the client's transference neuroses and their ability to work with the therapist. Greenson first coined the term working alliance in 1965 to describe the positive rapport between client and therapist as a rational protection against the client's more irrational beliefs. 
Bordin (1979) utilized Greenson's concepts of the working alliance and Carl Roger's belief in the client as an agent in the process of change in conceptualizing working alliance. He first described the working alliance as an agreement between the client seeking change and the therapist willing to act as a facilitator of change. Bordin (1994) later defined the working alliance as a pan-theoretical construct that allows the client to accept and follow through in treatment, or as the key factor to achieve change through psychotherapy. The working alliance demands collaboration between the therapist and the client (Horvath \& Symonds, 1991).

Bordin's 1979 model of the therapeutic relationship includes agreement on the goals of therapy, agreement on the tasks of therapy, and development of the bond. The goals component is described as the client and therapist's formulation and agreement upon what is hoped to be accomplished in therapy. The tasks component can be described as the agreement on techniques, procedures, and behaviors to accomplish the goals of therapy. The bond in therapy may include many aspects of the relationship between therapist and patient but essentially describes how the patient and therapist view the relationship, either positively or negatively.

The strength of the alliance can be measured by the goodness of fit between the patient and therapist and requires a committed engagement between the therapist and client to focus on therapy-specific tasks and the overall treatment goals (Hartley \& Strupp, 1994; Horvath \& Luborsky, 1993). Horvath (2001) suggested that a little over half of psychotherapy's positive effects can be attributed to the quality of the alliance. Thus, the client and therapist must both have a willingness to become involved in the 
treatment process for the alliance to be effective and psychotherapy to be viewed positively.

Developing the Working Alliance in Psychotherapy. Horvath and Luborsky (1993) and Horvath and Symonds (1991) indicated that the alliance appears to develop within the first five sessions, typically peaking by the third session. These authors also suggested that the alliance predicts therapy outcome equally for all theoretical orientations, and the client's ratings of alliance are more predictive of outcome than either therapists' or observers' ratings. Other research has concurred with these findings that alliance is established within the first three sessions and remains largely stable throughout treatment (Eaton, Abeles, \& Gutfruend, 1988; Horvath, 2001). These findings emphasize the need for the therapist to establish a positive working alliance with the client early in treatment.

However, therapists must tread carefully when initially assessing the strength of the working alliance. Two studies demonstrated that a high initial alliance after the first session or intake was related to early attrition and poor outcomes (Florsheim, Shotorbani, Guest-Warnick, Barratt, \& Hwang, 2000; Joyce \& Piper 1998). A high initial working alliance rating may be a result of unrealistic expectations on the part of the client or overestimation of the therapist's skills. The researchers suggested that lower initial ratings of working alliance that gradually increased over time were better predictors of positive outcome in psychotherapy.

Horvath and Luborsky (1993) pointed to two critical phases in the development of working alliance. In the first phase, which occurs within the first five sessions, the client 
and therapist must work on building trust and collaborate on goals. The second phase requires the therapist to challenge the client's neurotic patterns and old ways of thinking. The client could react negatively at this stage and cause the working alliance to weaken. Thus, the working alliance can be rated differently over the course of treatment and may be affected by several client and therapist variables.

Horvath (2001) suggested three client variables that may affect the quality of the working alliance: severity of the problem, the type of client impairment or psychological distress, and the quality of the client's attachments or object relations. Eaton et al. (1988) found that higher levels of client psychological distress adversely affected the development of the working alliance in an adult population. Horvath (2001) suggested that alliance building with adult clients diagnosed with relational problems or attachment disorders may be more difficult than with other adults. Eltz et al. (1995) found that prolonged maltreatment produced initial difficulties with working alliance formation in a study of maltreated adolescents. This could be explained by the maltreated adolescent's increased wariness to trust others and feeling unsafe in new environments. However, despite the initial difficulties with alliance formation Eltz et al. (1995) concurred with Horvath and Luborsky (1993) that a positive working alliance was the best predictor of therapeutic outcome.

The therapist factors that have been shown to affect the formation and quality of the working alliance include communication skills, empathy, openness, and a willingness to engage in collaboration, and level of experience and training (Horvath, 2001). Therapists must exude empathy and provide a supportive and safe environment for the 
client. Hill (2005) suggested that if the client feels safe with the therapist, exploration of the client's problems and personality can begin and will result in a stronger working alliance.

Developing Working Alliance with Children and Adolescents. Historically, adult psychotherapy research has placed emphasis on the role of the therapeutic relationship and the working alliance as important variables for predicting psychotherapeutic outcomes (Horvath \& Greenberg, 1986; Luborsky, Crits-Christoph, Mintz, \& Auerbach, 1988). However, establishing a positive working alliance in psychotherapy can be extremely challenging with children and adolescents. In research on adolescent alliance several relationship variables, including therapists' warmth, involvement with the client, and the developing bond have been associated with positive outcomes (Creed \& Kendall, 2005). Anna Freud initially researched the concept of affectionate attachment in treating children. This form of attachment appears to represent the bond in psychotherapy (Zack, Castonguay, \& Boswell, 2007). This attachment to the therapist and the formation of a warm, accepting environment or bond dictated the historical course of interventions with children and adolescents.

Adult psychotherapy literature has long focused on the working alliance and its three components, goals, tasks, and bonds (Bordin, 1979). Research with children and adolescents has utilized Bordin's model to conceptualize the working alliance with this population. Several studies have found the model's goals, tasks, and bonds to be inapplicable to youth psychotherapy (DiGuiseppe et al., 1996; Faw et al., 2005; Shirk \& Saiz, 1992). Faw et al. (2005) found the bond and task components to be the most 
relevant factors to the development of the working alliance. The bond can be described as the client's orientation to the therapist and to therapy and the task as participation in and collaboration with the activities of therapy (Faw et al., 2005). Research has also shown that the goals component of Bordin's (1979) model may not be recognized by children and adolescents due to its relative similarity to the tasks component. This phenomenon has been supported in adult working alliance literature in that adult clients have some difficulty distinguishing between the goals and tasks on the Working Alliance Inventory (Herzog, 2007; Horvath \& Bedi, 2002).

Several factors may contribute to the lack of congruency of Bordin's model for youth versus adult psychotherapy. Children and adolescents are often not self-referred for therapy. They may be unaware that their parent perceives a specific problem with their behavior or refuse to recognize that a problem exists. They may be unmotivated to change or be unconcerned about the level of stress the stated problem causes them or their immediate family. Cognitive abilities and developmental levels may also play a role, as children and adolescents who are more self-aware or possess greater intellectual capabilities may recognize the need for treatment (Zack et al., 2007).

DiGuiseppe et al. (1996) proposed that aspects of the therapeutic alliance may differ in prominence when predicting therapy outcome across age. Church (1994) stated that some therapists encounter difficulties when working with adolescents due to a failure to recognize the adolescent's need for autonomy and how that may affect the therapeutic relationship. Adolescents appear most concerned with the agreement on the tasks of therapy since dependence, independence, and self-determination are important 
developmental issues for them (DiGuiseppe et al., 1996). They are sensitive to having others' goals imposed on them and they want to choose their own way of doing things. Traditional child and adolescent psychotherapies may fail to develop effective working alliances due to their primary focus on the development of the bond and neglect in achieving agreement on the tasks of therapy.

Working alliance may be difficult to establish with adolescents as they often fluctuate between rejecting help and asking adults for guidance (Church, 1994). Several studies suggested that children and adolescents with externalizing disorders, primarily oppositional and conduct disorders do not benefit from traditional therapy techniques because they are typically unmotivated and unwilling to work with the therapist (DiGuiseppe et al., 1996; Sherwood, 1990; Weisz, Weiss, Alicke, \& Klotz, 1987). Dolan, Arnkoff, and Glass (1993) suggested that adolescents with internalizing disorders, such as depression or anxiety, may establish agreement on the goals and tasks of the working alliance more readily due to their emotional discomfort and their comparative lack of difficulty engaging with authority figures. Adolescents with anxious or avoidant attachment styles were found to report more severe symptoms prior to beginning psychotherapy and thus affected the quality of the developing working alliance (Dolan et al.,1993).

Working Alliance and Outcome with Children and Adolescents. Karver et al. (2008) indicated there is a relationship between treatment participation and treatment outcome in studies with adolescents. If the client perceives the working alliance positively, there may be more willingness to engage in treatment. This willingness may 
involve completion of therapeutic tasks including homework, cooperating with therapist, and discussing feelings (Karver et al., 2006).

Several recent studies (Karver et al., 2006; Karver, Shirk, Handelsman, Fields, Crisp, Gudmundsen et al., 2008; Shirk \& Karver, 2003) have shown associations between therapeutic relationship variables, including working alliance, and treatment outcomes in child and adolescent psychotherapy. Shirk, Gudmundsen, Kaplinski, and McMakin (2008) found adolescent self-report of early alliance with therapists predicted symptom change in cognitive-behavior treatment for depression. Additionally, information about client-therapist alliance, client-family satisfaction, and client-family involvement has been shown to be predictors of success during treatment (Lambert, 2005; Miller, Hubble, \& Duncan, 1995).

There is evidence to suggest that certain therapist behaviors may be critical to the formation of a positive working alliance with adolescents. Diamond et al. (1999) found that therapists' interventions in the first two sessions were related to alliance formation in a population of adolescent substance abusers. Therapists who presented themselves as allies, attended to the adolescents' emotional experiences, addressed the issues of trust and confidentiality in the therapeutic relationship, and formulated meaningful goals were successful in forming positive alliances. Karver et al. (2008) discovered that therapist behaviors including pushing the child or adolescent to talk, overemphasizing information from a prior session, and criticism negatively affected the development of the working alliance. Creed and Kendall (2005) concurred with these findings that therapists who were perceived to be pushing the client to talk had lower alliance ratings. These studies 
support the idea that therapists who attend to their adolescent clients' needs while emphasizing their role in support of the adolescents' developing autonomy may have the most success in forming a positive working alliance.

Measuring Working Alliance. Working alliance has become easier to measure in recent years, as a number of alliance assessment techniques have been developed to measure the working alliance in adult populations. These measures have shown strong intercorrelations despite their focus on different aspects or definitions of the alliance (Horvath \& Symonds, 1991). The Working Alliance Inventory (WAI) was developed by Horvath and Greenberg (1986) as a self-report questionnaire that produces a measure of the degree to which the therapist and client have developed a therapeutic alliance. The WAI has a global index measure of alliance as well as measures of the three alliance components, goals, tasks, and bond. The WAI has theoretical roots in Bordin's (1979) conceptualization of the working alliance. The instrument has 36 items rated on a Likert scale ranging from one (never) to seven (always). It is an instrument that can be administered quickly to a client, therapist, or non-participating observer.

There are several forms of the WAI including the WAI-S (Short Form) developed by Tracy and Kokotovic (1989) and the WAI-SR (Short Form Revised) developed by Hatcher and Gillaspy (2006). The WAI-SR was developed as a 12-item self-report measure with parallel forms for third party raters and therapists. The measure produces a total alliance score as well as scores for the three subscales of goals, tasks, and bond.

The WAI and its various forms have been shown to be reliable and valid for measuring working alliance. The reliability estimates range from .79 to .97 (Hansen, 
Curry, \& Bandalos, 2002). High internal consistency has also been shown, with scores ranging from .85 to .98 using Cronbach's alpha (Hansen et al., 2002; Horvath \& Greenberg, 1986). The WAI has been shown to have significant correlations between WAI ratings and therapy outcome in both inpatient and outpatient settings (Horvath \& Greenberg, 1986; Munder et al., 2010). There are several other measures to assess the development of working alliance; including the California Psychotherapy Alliance Scales (CALPAS; Marmar, Weiss, \& Gaston, 1989), the Penn Helping Alliance Rating System (Luborsky, Crits-Cristoph, Alexander, Margolis, \& Cohen, 1983), and the Vanderbilt Therapeutic Alliance Scale (VTAS; Hartley \& Strupp, 1983). In a meta-analytic study of therapeutic alliance and outcome by Martin et al. (2000), the Penn scales, the Vanderbilt scales, the CALPAS, and the WAI were moderately correlated with outcome. Martin et al. (2000) described the WAI as an appropriate measure for a variety of research due to its ability to measure alliance in many types of therapies. Overall, the WAI has been found to be the most popular measure of working alliance due to its familiarity to both researchers and clinicians (Hanson, Curry, \& Bandalos, 2002).

Several studies have focused on measuring the working alliance with adolescent samples (Diamond et al., 1999; DiGuiseppe et al., 1996; Faw, Hogue, Johnson, Diamond, \& Liddle, 2005). In all of the previously mentioned studies, the working alliance construct has been adapted from Bordin's (1979) pan-theoretical conceptualization and utilized in various measurement tools. DiGuiseppe et al. (1996) adapted Horvath and Greenberg's WAI (1989) to accommodate a lower reading level for adolescents aged 11 to 18 years old. Their version of the WAI was called the Adolescent Working Alliance 
Inventory and produced acceptable internal consistency scores. However, the AWAI appeared to measure one general alliance factor rather than the three subscales of goals, tasks, and bond as measured by the WAI. As a result, DiGuiseppe et al. (1996) suggested that measuring the alliance with adolescents may be one-dimensional due to adolescents' inability to understand the goals, tasks, and bonds in Bordin's concept of the therapeutic relationship.

Several types of working alliance scales have been developed for adolescent populations. The Therapeutic Alliance Scales for Children (TASC) was created by Shirk and Saiz (1992) as a measure of alliance with both child and therapist rating forms. The Adolescent Therapeutic Alliance Scale (ATAS) was developed by Johnson, Hogue, Diamond, Leckrone, and Liddle (1998) as an observer-rated measure of the therapistadolescent client working alliance in any psychotherapy setting. The ATAS (1998) was modified from the Vanderbilt Therapeutic Alliance Scale (VTAS; Hartley \& Strupp, 1983). Shirk, Gudmundson, McMakin, Dent, and Karver (2003) created the Adolescent Alliance Building Behavior Scales based on a review of the literature and existing treatment manuals for adolescents with internalizing disorders. The Adolescent Alliance Building Behavior Scales gather information about various aspects of the therapist-client relationship including the therapist's ability to formulate goals, collaborate with the client, acknowledge support and retain client information.

Working alliance has been a robust indicator of outcome in individual psychotherapy (Martin, Garske, \& Davis, 2000). Working alliance has been identified as a relationship construct in group psychotherapy that may improve outcome and 
symptoms along with variables including group cohesion, group climate, and empathy (Johnson, Burlingame, Olsen, Davies, \& Gleave, 2005). Research has shown many of these constructs to be related to one another. In fact, some research has equated group cohesion with working alliance in group psychotherapy (Piper et al., 1983). The next section describes the construct of group cohesion and its relationship to working alliance. Development of group cohesion with children, adolescents, and adults is delineated and techniques for measurement of group cohesion are outlined.

\section{Group Cohesion}

Group cohesion has been shown to contribute to greater therapeutic gains in group therapy (Burlingame, Fuhriman, \& Johnson, 2001). However, more often in group psychotherapy the working alliance refers to the relationship between the therapist and group member and cohesion refers to the relationship between the group members (Crowe \& Grenyer, 2008). Budman et al. (1989) described group cohesion as the bond existing between group members that allow them to trust one another and work together toward shared goals. Piper et al. (1983) described group cohesion as a basic bond that can be divided into the bond between the group member and the group as a whole, the other group members, the therapist, and the therapeutic work. Marziali, Munroe-Blum, and McCleary (1997) defined the patient-therapist relationship as group alliance or working alliance and defined the relationships between the group members as group cohesion.

Marziali et al. (1997) and van Andel et al. (2003) measured group cohesion and working alliance in group therapy with adult patients using different rating scales. Both 
studies found group cohesion and working alliance represent different relationships in the group process, suggesting it is important to separate the bond between the therapist, defined as working alliance, and the bond between the individual group member and other group members, defined as group cohesion. These researchers also stressed the importance of taking into account the range of individual differences and group developmental processes on outcome in group psychotherapy.

Developing Group Cohesion with Children and Adolescents. While there is little research on the process of group psychotherapy with children and adolescents, there is a strong need for such research to develop a theory of group work with this population (Shechtman, 2001). Children and adolescents across cultures may approach group psychotherapy differently than adults and be more willing to self-disclose during the initial stages of group development (Leichtentritt \& Shechtman, 1998). This finding is consistent with the developmental needs of children and adolescents in that they are focused on making friends and developing social skills, and may be more receptive to feedback and intervention than adults in group psychotherapy. In this manner, cohesion ratings may be higher during initial stages of group psychotherapy if therapists can work to develop therapeutic relationships and clearly delineate the goals of the group while demonstrating empathy and acceptance of members.

Whatever the definition, cohesion is important in group psychotherapy interventions and requires the group leaders to understand both the concept of cohesion and how to facilitate it amongst the group members. Group leaders must also account for the overall group climate, which can be thought of as the therapeutic atmosphere in 
groups (Bakali, Baldwin, \& Lorentzen, 2009). Group climate has been described in three dimensions, engagement, avoidance, and conflict. Researchers have suggested that fluctuations in these components of group climate correspond with different stages in the progressive models of group development (MacKenzie, 1983). In an attempt to identify and track the development of group processes, MacKenzie (1983) developed the Group Climate Questionnaire. This assessment measure and others developed to measure group climate and group cohesion are outlined in the next section.

Measuring Group Cohesion. One of the first measures of cohesion was the Cohesiveness Scale developed by Gross in 1957 and modified by several others, including Yalom and also Stokes (Budman et al., 1989). Other measures of group cohesiveness include the Harvard Community Health Plan Group Cohesiveness Scale (Budman et al, 1989) which consists of five subscales and a global scale that require the group member to rate the overall functioning of the group. MacKenzie and Livesley (1983) originally described six developmental stages of engagement, differentiation, individuation, intimacy, mutuality, and termination and developed the Group Climate Questionnaire (GCQ) to address these stages. Factor analysis of the original, long version of the Group Climate Questionnaire found eight scales including engagement, support, practicality, disclosure, cognition, challenge, conflict, and control (MacKenzie, 1983). The shortened version, the Group Climate Questionnaire Short Form (GCQ-S; MacKenzie, 1983), is a 12-question self-report assessment measuring the three group climate dimensions, Engaged, Avoiding, and Conflict. Engaged is derived from the scales of engagement, support, disclosure, challenge, and cognition and indicates how 
important the group is to its members. A high score on this dimension represents a positive working atmosphere. Avoiding is derived from the control scale of the long version of the GCQ and describes the reluctance of group members to take responsibility for change. A high score on this dimension may suggest avoidance of group issues and difficulty interacting with group members. The third dimension, conflict, describes interpersonal tension between the group members.

The GCQ is the most widely used cohesion measure and has several advantages in that it can be administered sequentially, it is easy to complete and requires only a few minutes of the group member's time, and can alert group therapists to problems in the group process and development quickly. The GCQ-S subscales have high internal consistency, with alpha coefficients ranging from 0.88 to 0.94 (Crowe \& Grenyer, 2008). The GCQ-S is one of the most frequently used measures of group process and has been tested in a variety of settings (Bakali, Baldwin, \& Lorentzen, 2009).

Group psychotherapy is increasingly popular as a means of reaching multiple clients at once and has demonstrated positive outcomes with a variety of presenting problems across all ages, including but not limited to substance abuse, eating disorders, aggressive or oppositional defiant behavior, and depression (Franko, 1997; Gusella, Butler, Nichols, \& Bird, 2003; Shechtman, 2001; Velasquez, Maurer, Crouch, \& DiClemente, 2001). Efforts to predict the variables contributing to positive therapy outcome have been made in both individual and group therapy treatment over the last several decades. The working alliance and group cohesion have been outlined as two such predictors (Crowe \& Grenyer, 2008; Martin, Graske, \& Davis, 2000). Another 
potential construct affecting outcome in both individual and group psychotherapy is the individual's readiness to change a problem behavior. Motivation to change is part of Prochaska and DiClemente's (1982) integrative theory of behavior change. The Transtheoretical Model is described in detail in the next section and its implications for research and clinical practice are highlighted.

\section{The Transtheoretical Model and the Stages of Change}

The Transtheoretical Model was developed by Prochaska and DiClemente (1982) and focuses on the decision-making of the individual and describes how individuals modify a problem behavior or acquire a positive behavior. The Transtheoretical Model involves the individual's emotions, cognitions, and behavior and employs as its central organizing construct the Stages of Change (Velicer, Prochaska, Fava, Norman, \& Redding, 1998). Alternative theories of change describe change as a singular event while the Transtheoretical Model posits the stages of change as a temporal dimension describing when change occurs for the individual in progression through five stages (Brogan, Prochaska, \& Prochaska, 1999).

The stages of change construct within the Transtheoretical Model incorporates several theories related to behavior change, including the process of changing, potential benefits and drawbacks to changing, temptations, and self-efficacy (Velicer, Prochaska, Rossi, \& DiClemente, 1996). Prochaska and DiClemente (1982) initially posited four discrete stages of change, Precontemplation, Contemplation, Action, and Maintenance but later expanded to a five-stage model of change to include preparation or determination between precontemplation and contemplation (McConnaughy et al., 1983; 
Prochaska \& DiClemente, 1992). Prochaska and Norcross (2002) initially described the stages as progressing in a linear sequence, but research in the fields of addiction and health psychology has shown individuals often relapse or regress back into earlier stages. Thus, it is more appropriate to conceptualize individuals as moving through the stages in a spiral fashion, with the tendency to cycle back to previous stages.

Stages of Change. The Precontemplation stage describes individuals who do not necessarily recognize a problem and are not motivated to change in the foreseeable future. Precontemplators are categorized by their lack of intent to change in the next six months. When individuals present to psychotherapy in the precontemplation stage, they are often pressured or even coerced to attend by family, employers, or courts (Prochaska, DiClemente, \& Norcross, 2003). Precontemplative individuals may be uninformed or under-informed about the consequences of their behaviors or may have tried to change and were unsuccessful. They are often categorized by other theories as unmotivated or resistant to change, when traditional psychotherapy interventions typically are not designed for precontemplative individuals (Velicer et al., 1998).

The Contemplation stage describes individuals who may be aware of the problem but have not made a conscious decision to change. Contemplative individuals typically have intent to change in the next six months. However, this stage can last for long periods and there appears to be a great deal of ambivalence and vacillation as the individual weighs the pros and cons of changing behavior. Individuals with addictive behaviors often struggle with their feelings about and the effort and loss it will cost to overcome the problem (Prochaska et al. 2003). 
Preparation is the stage that combines intention and behavior. Individuals in this stage have intentions to take action to change and may have attempted to unsuccessfully change their behaviors in the past year. Prochaska et al. (2003) originally conceptualized this stage as decision-making, or determination, and research has shown it to be the beginnings of the action stage. The Transtheoretical Model suggests these individuals should be recruited or targeted for action-oriented change programs and interventions.

Preparation is followed by the Action stage, in which the individual takes steps to modify his or her behavior to overcome their problems. The most progress is made in this stage due to the individual actively deciding to make changes and following through. The action stage represents observable behavior changes in the individual and also when vigilance against relapse is critical.

The final stage is Maintenance, which is characterized by attempts to prevent relapse or to complete the changes initiated in the Action stage. These individuals are most confident about their ability to continue the change process.

Traditional psychotherapy interventions are designed for self-referred clients in the contemplative or action stages. These individuals typically have more insights about their emotions and behaviors that have moved them from the precontemplative stage to the contemplative, preparation, or action stages before entering therapy. However, addiction research has shown that most addicted individuals are not in the action stage; rather they present to treatment in the precontemplation or contemplation stages (Prochaska et al., 2003). People mandated for treatment, substance abusers, or clients who attend therapy at others' insistence typically enter in the precontemplative stage and 
are less willing to change. Adolescents are similar to these hard-to-treat populations in that they are not usually self-referred for treatment.

Measuring Stages of Change. McConnaughy et al. (1983) were among the first to introduce a multidimensional stages of change measure, initially called the Stages of Change Scale and renamed the University of Rhode Island Change Assessment (URICA). The URICA is the most widely studied measure of readiness to change and is intended for use in a variety of clinical contexts (Sutton, 2001). The URICA is focused on a general "problem" and can assess change readiness regarding a range of problems. The URICA consists of 32 items and provides a continuous measure of differences in attitude for individuals in each of the four stages of change. McConnaughy et al. (1983) designed the measure to depict the Precontemplation, Contemplation, Action, and Maintenance stages of change. This creates a readiness profile of four subscale scores rather than placement at a particular stage (Sutton, 2001). After the URICA was developed in 1983, a fifth stage of change was proposed, Preparation, which describes clients' commitment and belief in their ability to change (Prochaska et al., 1994). This stage is often included in studies that administer the URICA.

Sutton (1996) indicated it may be more appropriate to conceptualize individuals on a continuum of change rather than as progressing through a series of stages, thus utilizing this score profile is appropriate. The URICA has been found to have good internal consistency with both adult and adolescent samples (Derisley \& Reynolds, 2002; McConnaughy et al., 1983; Napper et al., 2008). The measure has been utilized in studies with specific behavior problems, including eating disorders, alcoholism, drug use, 
smoking cessation, and male battering behaviors (Cohen et al., 2005; Gusella, Butler, Nichols, \& Bird, 2003; Herzog, 2007; Levesque, Gelles, \& Velicer, 2000; Napper et al., 2008).

There are several other assessment measures to determine readiness for change, including the Stages of Change Readiness and Treatment Eagerness Scale (SOCRATES) developed by Miller and Tonigan (1996) and the Readiness to Change Questionnaire (RCQ) developed by Rollnick, Heather, Gold, and Hall (1992). Both of these measures were designed to target alcohol abuse and focus specifically on alcohol addiction as the "problem behavior." Gusella et al. (2003) developed the Motivational Stages of Change for Adolescents Recovering from an Eating Disorder (MSCARED) which utilized Prochaska and DiClemente's 1982 model with an adolescent population to determine readiness to change eating disorder behavior. The URICA, in contrast, focuses on the clients' general "problem" and allows the individual to determine which behavior they would like to focus on changing.

McConnaughy et al. $(1983 ; 1989)$ initially used the URICA to examine stages of change for adults entering psychotherapy. Derisley and Reynolds (2002) utilized the URICA and found it to have high internal consistency among a sample of adults. In several studies, the URICA has been utilized with adolescent samples with severe mental health issues and adolescents engaged in a smoking cessation program (Cohen et al., 2005; Greenstein et al., 1999; Hemphill \& Howell, 2000; Herzog, 2007). These studies have utilized the URICA with positive results. For instance, Greenstein et al. (1999) determined the URICA was an appropriate measure of readiness for change for a 
population of juvenile offender adolescents with emotional, behavioral, and/or severe psychological problems. Cohen et al. (2005) and Hemphill and Howell (2000) utilized the URICA with populations of detained adolescent offenders and found the measure to be as appropriate in adolescent samples as adult samples in assessing readiness for change. While the URICA was found successful in measuring adolescents' readiness to change, some researchers cautioned that adolescents may not view the change process in the same manner as adults (Hemphill \& Howell, 2000). Adolescents more than adults may need coaching and assistance in learning skills to aid them in coping with the problems related to each stage of change.

\section{Working Alliance and Stages of Change}

An area that has been studied with children and adolescents but has not been related to working alliance is assessing the client's level of motivation to participate in treatment and how it may affect the development of the working alliance. The clients' level of motivation, or stage of change beliefs, may predict their involvement and engagement in treatment. Fitzpatrick and Irannejad (2008) suggested that while there is an empirically supported relationship between working alliance and outcome there may also be a relationship between readiness for change and alliance-building. The clients' readiness for change, or their stage of change beliefs, may have a positive or negative effect on the development of the alliance. Emmerling and Whelton (2008) found individuals who moved from a lower stage of change to a higher stage indicated stronger working alliance than those who did not move to a different stage. It seems worthwhile 
to investigate this relationship in adolescent populations given this group's unique needs and therapeutic challenges.

There has been little research investigating the role of the URICA in predicting therapy engagement or the therapeutic alliance (Derisley \& Reynolds, 2000). The Transtheoretical Model proposes that the individuals' stages of change beliefs, or readiness to change, are critical in predicting change in treatment. The stages of change have been extensively researched in the fields of addiction and health psychology with both adult and adolescent populations. The majority of this research focuses on addictions, smoking cessation, weight management, HIV prevention, and male battering behaviors (Herzog, 2007; Levesque et al., 2000; Velicer, Fava, Prochaska, Abrams, Emmons, \& Pierce, 1995; Prochaska, Redding, Harlow, Rossi, \& Velicer, 1994). Addictions researchers propose the Transtheoretical Model and the stages of change can be applied to general psychotherapy interventions. The model has shown the individual's stage of change beliefs are an important factor in predicting the client's progress in treatment (Prochaska et al. 1992). Individuals who enter treatment in the precontemplation stage of change have difficulty engaging in treatment and have greater attrition rates. It can be assumed that these clients will also have difficulty forming a positive working alliance with their therapist.

McConnaughy et al. (1989) posited that individuals who enter treatment at the Precontemplation or Contemplation stage are less likely to initiate change and may be more likely to end treatment prematurely compared to individuals who enter therapy in the Action stage. Measuring readiness for change at the beginning of therapeutic 
processes may assist clinicians in determining the client's level of acknowledgment of problems and commitment to change (Cohen et al., 2005). It may also assist in developing appropriate treatment interventions to match the client's stage of change beliefs.

Client readiness to change and working alliance in psychotherapy are largely separate constructs. The concepts of client readiness to change, or stage of change beliefs, and the development of the working alliance have not been widely studied in either adult or adolescent samples. In a study of the impact of pretreatment counseling expectations on the development of the working alliance, Patterson, Uhlin, and Anderson (2008) investigated a population of adults in an outpatient psychotherapy setting and found clients with higher pretreatment expectations and a willingness to commit to therapy had higher working alliance ratings. The researchers concluded that therapists' should assess clients' pretreatment expectations at the outset of therapy to predict more favorable outcomes. While this study did not directly investigate clients' stage of change beliefs, pretreatment expectations and motivation for psychotherapy were shown to be important for predicting working alliance development.

Several studies have investigated whether the stages of change model could predict attendance and working alliance in adult samples (Derisley \& Reynolds, 2000; Emmerling \& Whelton, 2008; Principe, Marci, Glick, \& Ablon, 2006). Principe et al. (2006) examined the relationship between the contemplation stage of change, formation of the working alliance, degree of psychological distress, and attendance in psychotherapy. Both Derisley and Reynolds (2000) and Principe et al. (2006) found that 
higher contemplation scores predicted positive working alliance ratings on the Working Alliance Inventory. Emmerling and Whelton (2008) found that individuals who progressed to a higher stage of change from a lower stage over the course of treatment had higher working alliance ratings. Derisley and Reynolds (2000) found low contemplation scores predicted premature termination from therapy. Emmerling and Whelton (2008) found the working alliance successfully mediated the relationship between stages of change and symptom improvement for participants.

One study examined the relationship between working alliance and stage of change beliefs in an adolescent sample. Fitzpatrick and Irannejad (2008) studied whether adolescents' readiness to change for a specific problem was related to the working alliance with their therapists. Participants included 43 students who received counseling at a Canadian high school. Results indicated adolescents in the action stage of change had more positive alliance ratings with their counselors than those with precontemplation scores.

These results from both adolescent and adult populations suggest that clients who present to therapy in the contemplation stage of change form more positive working alliances than those in the precontemplative stages of change. Consistent with previous research, the client's level of psychological distress did not predict alliance formation. Principe et al. (2006) cautioned that therapists need to nurture the formation of the working alliance with contemplative individuals by attending to and accepting the client's resistance, as ambivalence is the key component of contemplation. 


\section{Chapter Summary}

There is limited research on the working alliance with children and adolescents and even less research on this population's readiness to change a "problem" behavior in psychotherapy. In contrast, research on the working alliance with adults in psychotherapy has been one of the most widely studied constructs in psychotherapy literature (Horvath, 2001). There is a need for psychotherapy research specifically geared toward children and adolescents over simply generalizing adult research to interventions with children and adolescents. As more treatment with children and adolescents is conducted in a group format, it is necessary to investigate the variables that affect the therapeutic relationship in group psychotherapy as well.

The constructs of working alliance and stage of change beliefs have been shown to impact the process of change in psychotherapy, but there are few studies that link the two constructs together and investigate their influence on psychotherapy (Derisley \& Reynolds, 2002; Emmerling \& Whelton, 2008; Fitzpatrick \& Irannejad, 2008; Principe et al., 2006). Research to date has shown the working alliance greatly impacts the psychotherapy relationship and has also shown the benefits of applying the Transtheoretical Model to psychotherapy interventions. Expanding this research is needed to better understand the expectations of children and adolescents and tailor interventions to meet these needs. A greater understanding of the variables that influence psychotherapy may allow therapists to serve this population more effectively. The next chapter outlines this study's research methodology and design. 


\section{Chapter 3}

\section{METHODOLOGY}

There were several purposes of the current study. One purpose was to investigate adolescents' perceptions of the quality of the working alliance in group psychotherapy over time. Additionally, the study investigated the adolescents' stage of change beliefs measured at the first and last session of the IOP group intervention. The research also looked at the relationship between adolescent clients' readiness to change and their ability to develop a working alliance with their therapist. Another purpose of this study was to determine the relationship between parents' beliefs about their adolescents' stage of change and the adolescents' stage of change beliefs. A quantitative research approach was utilized.

\section{Participants}

Participants were male and female adolescents receiving outpatient counseling services through a psychiatric hospital in a large Western city. There were 25 participants who initially presented to the IOP group and provided informed consent for this study. Five of these initial 25 participants dropped out after only completing session one for reasons described later in this section. Twenty participants completed the IOP group and the majority of study measures. Of these final 20 participants, 15 participants completed the IOP group and all study measures. The ethnic makeup of the clients 
served at the hospital is approximately $60 \%$ Caucasian, 20\% Hispanic, $10 \%$ African American, 5\% Asian American, and 5\% mixed race. The socioeconomic makeup of the hospital's clients is predominantly middle-to upper-middle class. The current study attempted to achieve a comparable ethnic makeup and socioeconomic level to the hospital population. In this section the demographic statistics for both adolescent participants and their parents as well as inclusion and exclusion criteria for the study are described.

Adolescents’ Demographic Information. A researcher-designed demographic questionnaire (Appendix C) was used to collect information regarding participants' demographic characteristics. The adolescent demographic information was examined to determine whether any significant differences existed between participants according to gender, age and ethnicity. There were 25 adolescent participants who completed demographic information at the beginning of the IOP group but five of these participants dropped out after the first session. Of these, two decided that individual therapy would be a better fit than group therapy and three chose to drop out due to their insurance not reimbursing for the IOP group. The initial 25 participants' demographic information is described below followed by a description of the demographic information for the 20 adolescent participants who completed the IOP group.

Of the 25 adolescent participants who began the study there were more male $(n=$ 15) than female $(n=10)$ participants, or $60 \%$ and $40 \%$, respectively. The mean age of these adolescents was 14.7 years $(M=14.7$; $\mathrm{SD}=1.35)$. The majority of participants were Caucasian $(n=18 ; 72 \%)$, with the next highest ethnic group being African 
American $(n=3 ; 12 \%)$ The remaining participants identified themselves as Hispanic/Latino/a, Asian/Pacific Islander, American Indian, or Other race, with $n=1$ or $4 \%$ each, respectively.

Twenty adolescent participants completed all or nearly all of the assessment measures and finished the IOP group. Of these 20 participants, there were more male $(\mathrm{n}=13 ; 65 \%)$ than female $(\mathrm{n}=7 ; 35 \%)$ participants. The mean age of these participants was 14.5 years $($ Mean $=14.5 ; \mathrm{SD}=1.36)$. The majority of participants were Caucasian ( $\mathrm{n}=15 ; 75 \%)$, three were African American (15\%), and remaining two identified as American Indian or Other race, with $n=1$ or $5 \%$ each, respectively. The modal grade level of participants in the study was eighth grade.

Parents' Demographic Information. For the parents of the initial 25 study participants, there were more females $(n=17)$ than males $(n=8)$, or $68 \%$ and $17 \%$, respectively. Eighteen parents were married (72\%) four were single (16\%), one parent was separated (4\%), and one was divorced (4\%). The majority of parent participants were Caucasian $(\mathrm{n}=21 ; 84 \%)$, with the next highest ethnic group identifying as Asian American $(\mathrm{n}=2 ; 8 \%)$, and one parent identifying as Other race $(4 \%)$ and one as Hispanic/Latino/a (4\%).

For the parents of the twenty completed study participants, there were more females $(n=16)$ than males $(n=4)$, or $80 \%$ and $20 \%$, respectively. Fourteen parents were married (70\%), three were single (15\%), and one parent fell into each of the categories of divorced, separated, or widowed (4\% each). The majority of participants' parents were 
Caucasian $(18 ; 90 \%)$, with one parent identifying as Other race $(5 \%)$ and one as Asian American (5\%).

The current study parallels the ethnic makeup of the clients served at the hospital except the current study does not have similar proportions of Hispanic/Latino/a participants. Comparisons of descriptive analyses between the 25 initial consented individuals and the 20 study completers found no differences with respect to age, ethnicity, or gender. See Table 1 for a summary of the adolescent participants' demographic characteristics with the total sample $(n=25)$ which includes the five participants who dropped out of the study and the sample from which complete or near complete data were collected $(n=20)$. See Table 2 for a summary of parent/caregiver demographic characteristics.

Table 1

Overview of Adolescent Demographic Characteristics for the 25 Individuals who Consented to the Study Including Study Dropouts and the 20 Study Completers

Demographics

Total Participants

Adolescent Age Range

13

14

15

16

17

\section{Adolescent Gender}

Male

Female

Adolescent Race/Ethnicity

Hispanic/Latino/a

Asian/Pacific Islander

African American

Caucasian

American Indian

Other
Frequency

Percentage

$100 \%$

Frequency

20

6

6

4

3

15

10

$24 \%$

$24 \%$

$24 \%$

$16 \%$

$12 \%$

$60 \%$

$40 \%$

$4 \%$

$4 \%$

$12 \%$

$72 \%$

$4 \%$

$4 \%$
Percentage

\section{$100 \%$}

$30 \%$

$20 \%$

$20 \%$

$15 \%$

$15 \%$

$65 \%$

$35 \%$

$7 \quad 35 \%$

0

0

$15 \%$

$75 \%$

$5 \%$

$5 \%$ 
Adolescent Grade Level

\begin{tabular}{lrrrr}
7 & 1 & $4 \%$ & 1 & $5 \%$ \\
8 & 8 & $32 \%$ & 7 & $35 \%$ \\
9 & 6 & $24 \%$ & 3 & $15 \%$ \\
10 & 3 & $12 \%$ & 3 & $15 \%$ \\
11 & 4 & $16 \%$ & 3 & $15 \%$ \\
12 & 3 & $12 \%$ & 3 & $15 \%$ \\
Adolescent Previous Treatment & & $68 \%$ & 14 & $70 \%$ \\
Yes & 17 & $32 \%$ & 6 & $30 \%$ \\
No & 8 & & & \\
\hline
\end{tabular}

Table 2

Overview of Parent/Caregiver Demographic Characteristics

\begin{tabular}{|c|c|c|c|c|}
\hline Demographics & Frequency & Percentage & Frequency & Percentage \\
\hline Total Participants & 25 & $100 \%$ & 20 & $100 \%$ \\
\hline \multicolumn{5}{|c|}{ Parent/Caregiver Gender } \\
\hline Male & 8 & $32 \%$ & 4 & $20 \%$ \\
\hline Female & 17 & $68 \%$ & 16 & $80 \%$ \\
\hline \multicolumn{5}{|l|}{ Parent Race/Ethnicity } \\
\hline Hispanic/Latino/a & 1 & $4 \%$ & 0 & 0 \\
\hline Asian/Pacific Islander & 2 & $8 \%$ & 1 & $5 \%$ \\
\hline African American & 0 & 0 & 0 & 0 \\
\hline Caucasian & 21 & $84 \%$ & 18 & $90 \%$ \\
\hline American Indian & 0 & 0 & 0 & 0 \\
\hline Other & 1 & $4 \%$ & 1 & $5 \%$ \\
\hline \multicolumn{5}{|c|}{ Parent Relationship Status } \\
\hline Single & 4 & $16 \%$ & 3 & $15 \%$ \\
\hline Married & 18 & $72 \%$ & 14 & $70 \%$ \\
\hline Separated & 1 & $4 \%$ & 1 & $5 \%$ \\
\hline Divorced & 1 & $4 \%$ & 1 & $5 \%$ \\
\hline Widowed & 1 & $4 \%$ & 1 & $5 \%$ \\
\hline Partnered & 0 & 0 & 0 & 0 \\
\hline
\end{tabular}

Inclusion and Exclusion Criteria. Participants for this study were recruited on a voluntary basis if they met the inclusion criteria including being between the ages of 1118 years old, enrolled in the Intensive Outpatient Program for group psychotherapy, and willingness to complete the demographic questionnaire and assessment protocols at the four data collection points during the group therapy intervention. 
No participants were excluded from the study; however the exclusion criteria included current suicidal or homicidal ideation or having been suicidal or homicidal in the last 14 days, active psychotic symptoms, including delusions, paranoia, or hallucinations or the parent or caregiver was not able to be present for sessions one and five of group psychotherapy.

\section{Instruments}

The assessment measures utilized in this study included the Working Alliance Inventory-Short Form Revised (WAI-SR; Hatcher \& Gillaspy, 2006), the Group Climate Questionnaire-Short (GCQ-S; MacKenzie, 1983), and the University of Rhode Island Change Assessment (URICA; McConnaughey et al., 1983) and are described in detail below. These assessment measures were retrieved from the public domain and can be found in Appendix D. The demographic questionnaires were developed by the researcher and can be found in Appendix C. Patient data from the Ohio Scales (Ogles, Melendez, Davis, \& Lunnen, 2001) were utilized with permission from the outpatient clinic from which the data were collected. Due to copyright constraints this measure was not included in the appendix.

Working Alliance Inventory-Short Form Revised (WAI-SR). The WAI-SR (Short Form Revised) was developed by Hatcher and Gillaspy (2006) as a 12-item self-report measure to measure the same three subscales as the Working Alliance Inventory (WAI; see Appendix D). Four questions address each of the three subscales of goal, task, and bond. The measure produces a total alliance score as well as scores for each of the three 
subscales. All items are rated on a 5-point Likert-type scale that ranges from 1 (never) to 5 (always). It has parallel forms for observers and therapists.

The WAI and its various forms have been shown to be reliable and valid for measuring working alliance. The reliability estimates range from .79 to .97 (Hansen, Curry, \& Bandalos, 2002). High internal consistency has also been shown, with scores ranging from .85 to .98 using Cronbach's alpha (Hansen et al., 2002; Horvath \& Greenberg, 1986). The WAI has been shown to have significant correlations between WAI ratings and therapy outcome (Horvath \& Greenberg, 1986). The WAI has also been shown to have overall reliability estimates for the complete instrument at .93 and for the subscales of the Bond, Goals, and Task at .88 to .91 . The WAI and its various forms have been deemed appropriate for fourth-grade reading levels (Horvath \& Greenberg, 1989). For purposes of analysis, the Total WAI-SR and all three subscale scores were utilized.

Group Climate Questionnaire (Short Form). McKenzie (1983) described group climate as a set of interactional dimensions and developed the Group Climate Questionnaire to study these dimensions. Factor analysis of the long version of the Group Climate Questionnaire found eight scales including engagement, support, practicality, disclosure, cognition, challenge, conflict and control (MacKenzie, 1983). The shortened version, the Group Climate Questionnaire Short Form (GCQ-S), is a 12question self-report assessment measuring the three group climate dimensions, Engaged, Avoiding, and Conflict (Appendix D). Engaged is derived from the scales of engagement, support, disclosure, challenge, and cognition and indicates how important 
the group is to its members. A high score on this dimension represents a positive working atmosphere. Avoiding is derived from the control scale of the long version of the GCQ and describes the reluctance of group members to take responsibility for change. A high score on this dimension may suggest avoidance of group issues and difficulty interacting with group members. Conflict describes interpersonal tension between the group members.

The GCQ requires the group members to evaluate the group as a whole and has several advantages in that it can be administered sequentially, it is easy to complete, requiring only a few minutes of the group member's time, and can alert group therapists to problems in the group process and development. The GCQ-S subscales have high internal consistency, with alpha coefficients ranging from 0.88 to 0.94 (Crowe \& Grenyer, 2008). The GCQ was chosen for the current study due to its widespread use and ability to measure group cohesion, which has been found to have correlations with working alliance in group psychotherapy literature. For purposes of analysis, only the GCQ-S (Engaged) score was utilized to investigate its relationship to the working alliance measured by the WAI-SR.

University of Rhode Island Change Assessment (URICA). McConnaughy et al. (1983) were among the first to introduce a multidimensional stages of change measure, initially called the Stages of Change Scale and renamed the University of Rhode Island Change Assessment (URICA; Appendix D). The URICA is the most widely studied measure of readiness to change and is intended for use in a variety of clinical contexts (Sutton, 2001). The URICA is focused on a general "problem" and can assess change 
readiness regarding a range of problems. The URICA is a 32 -item instrument that consists of four subscales of eight items each that address four stages of change, precontemplation, contemplation, action, and maintenance. The items are rated on a fivepoint Likert-type scale that ranges from 1 (strong disagreement) to 5 (strong agreement). The instrument provides a continuous measure of differences in attitude for individuals in each of the four stages of change. This creates a readiness profile rather than placement at a particular stage (Sutton, 2001).

Prochaska and Prochaska (2004) reported cluster analyses for the URICA demonstrated evidence for the Preparation stage to be included in the measure, particularly when individuals had high scores on both contemplation and action. In clinical research with adults, it has been purported that for people beginning therapy, $40 \%$ present in precontemplation, $40 \%$ present in contemplation, and $20 \%$ come to therapy in the preparation stage (Prochaska \& Prochaska, 2004). These percentages demonstrate the importance of including Preparation in measuring stage of change beliefs. In their study with adult psychotherapy clients, Emmerling and Whelton (2008) summed the individual subscale scores and assigned participants to one of the five stages of change based on their highest subscale score. In the case of identical scores for the contemplation and action subscales, the participants were assigned to the preparation stage based on Prochaska et al.'s 1992 research. This study utilized the same method of assignment as Emmerling and Whelton's (2008) study due the empirical research supporting Preparation as an accepted stage of change and an important part of the Transtheoretical Model (Prochaska et al., 1992). 
The URICA has been found to have good internal consistency, primarily with adult samples (McConnaughy et al., 1989, 1983; Derisley \& Reynolds, 2002), and has been utilized in studies with specific behavior problems, including weight control problems, alcoholism, smoking cessation, and male battering behaviors (Cohen et al., 2005; Levesque et al. 2000). The coefficient alphas for the four subscales range from .88 to .89 (McConnaughy et al., 1983). Fitzpatrick and Irannejad (2008) pilot-tested the URICA with a sample of students ages 11-13 years to determine if young adolescents would understand the language. The current study modified the instructions for the instrument to request the participant identify the problem for which they were presenting to therapy, consistent with Fitzpatrick and Irannejad's (2008) procedure.

Demographic Questionnaires. The demographic questionnaire was developed by the researcher (Appendix C) and collected information from the adolescent participants including: age, gender, ethnicity, level of education, and whether they had had previous mental health counseling. Information collected from the parent or caregiver included: gender, ethnicity, highest level of education achieved, and whether their adolescent had previous mental health counseling. The purpose of the demographic questionnaires was to gather relevant demographic information to provide information about the participants in the study. The demographic questionnaire was given to each participant and his or her parent or caregiver at the time of the first individual therapy session.

The Ohio Scales. At the outpatient clinic of the psychiatric hospital in which the study data were collected, the parent/caregiver was asked to complete the Ohio Scales prior to each IOP group session. For the purposes of this study, the data from 
participants' Ohio Scales assessments at the first and last session were utilized to determine pre-and post problem behavior ratings of overall functioning and problem severity. Thus, the data were provided to the researcher by the outpatient clinic and the Ohio Scales were not administered to participants by the researcher.

The Ohio Scales were designed as multi-rater, multi-content measures of clinical outcome across various settings for children and adolescents from ages 5-18 (Ogles, Melendez, Davis, \& Lunnen, 2001). The measures assess four domains; problem severity, functioning, hopefulness, and satisfaction with mental health services. The assessment measure is a Likert scale from zero to five, with zero being "not at all" and five being "all of the time." The overall score for each of the four categories is totaled with lower scores representing less problem behaviors, higher satisfaction ratings, and more hopefulness. For the functioning category, higher scores indicate healthier functioning. The assessment measure is useful because it can be completed by the adolescent (if over the age of 12), the parent/caregiver, and/or the therapist. The parent test-retest reliability has been shown to be .88 and has shown strong correlations with the Child Behavior Checklist problem total score (Ogles et al., 2001). The purpose of the Ohio Scales is to gather information about the child or adolescents' functioning through rating problem behaviors, level of hopefulness and satisfaction with mental health services.

\section{Procedure}

Description of Outpatient Clinic. Reasons for seeking outpatient counseling typically include relational problems, such as problems with parents, family members, or 
friends, depression and/or suicidal ideation, academic problems, anger issues, stress or anxiety-related problems, and self-esteem issues. Participants can be referred for outpatient counseling through various means, including through pediatricians and primary care physicians, school and community referrals, parent referral, and selfreferral. Patients can also transition from a higher level of care to outpatient therapy, such as a step-down from inpatient hospitalization or day treatment services.

This study gathered information from the Intensive Outpatient Program (IOP), a group psychotherapy intervention designed to meet the needs of clients discharging from inpatient hospitalization and day treatment programs as well as clients needing a more intensive treatment program than weekly outpatient therapy. The group was provided at the outpatient clinic by practitioners with varying levels of training and experience. These included licensed psychologists, licensed therapists and social workers, and trainees, including interns and practicum students. The IOP group met three times per week for 90 minutes each session. The parents and adolescents met as a group and then the group was split into a multi-family parent group led by two therapists and an adolescent group led by two therapists.

Informed Consent. After obtaining approval from the Institutional Review Board for Human Subjects (see Appendix E)., the recruitment of participants began The supervisors of the Intensive Outpatient Program (IOP) at the outpatient clinic were contacted in order to gain permission and access to the therapists providing services and to recruit clients for the study. Once they approved access to the therapists and clients in their clinic, an invitation flyer (see Appendix A) was distributed to the potential 
participants at the outset of their enrollment in the group either by the principal investigator or the IOP coordinator. An explanation of the study, the goals of the research, and the time required for participants was provided. In addition, they were provided with information regarding the methods of data collection and any potential harmful effects that might result from participation in the study.

The exact number of individuals that the invitation flyer was distributed to is unknown, as is the exact number of individuals that declined to learn more about or participate in the study. It is estimated that 45 individuals were given the invitation flyer. If the parent or caregiver agreed to learn more about the study, the principal investigator's phone number was provided and the parent contacted the principal investigator directly. If the parent or caregiver gave verbal consent to learn more about the study to the IOP coordinator or the principal investigator they were approached in person by the principal investigator at the time of their initial IOP group session and provided informed consent (see Appendix B).

To enroll participants in the study, the researcher met with participants and their parent or caregiver prior to their first IOP group. Each participant was provided with a consent form for his or her signature. Adolescent participants were asked to provide assent to participate if they are under the age of 15 and if they were over the age of 15 they were allowed to provide their written consent to participate. If the participant was under 15 years old, they were asked to provide verbal consent and written assent to participate in the study. The parent or caregiver provided written consent of their 
willingness to participate in the study. Each participant was given a copy of the consent and/or assent form for his or her records (Appendix C).

The informed consent included a brief explanation of the study, the methods of data collection, potential risks of participating in the study, and issues and limitations of confidentiality. Although demographic information was collected, participants' identifying information was altered to ensure confidentiality as data were analyzed and results reported. This was done through the use of a coding system in which each participant was given a number that was subsequently utilized on all assessment measures completed. After the participant signed the consent form, the researcher spent a few minutes explaining the reasons for conducting the study and explained the minimal risk of discomfort the participant may have experienced as a result of participation.

Difficulty Recruiting Participants. The researcher encountered more difficulty than was anticipated recruiting participants throughout the duration of the study. During the year that data were collected, the overall census for the IOP group was lower than expected. To maximize participants, the researcher employed several strategies including working closely with the IOP coordinator to monitor new referrals for IOP and sending weekly reminders to the IOP coordinator about the study's invitation flyer. Also, the researcher and IOP coordinator provided invitation flyers to IOP members who had agreed to be contacted about the study prior to the first IOP group, and the researcher began meeting with IOP group members who had agreed to learn more about the study during their first IOP group. The researcher also attended IOP group leader meetings to 
explain the study and ask that they remind participants to complete the necessary assessments after the group.

Additionally, the participants were provided with a token incentive in the form of a \$10 Target gift card for their participation and completion of assessment measures. Six months into data collection, this amount was increased to $\$ 15$ so as to attract more participants to the study. All changes to the study were submitted to the IRB. Despite efforts to enroll participants in the study and collect data for all assessment measures, the researcher was not able to acquire complete data for all participants. A more complete description of missing data and how it was handled can be found in Chapter Four.

Data collection. This study utilized several assessment measures to collect data from participants including a researcher-designed demographic questionnaire, the Ohio Scales, the University of Rhode Island Change Assessment (URICA), the Working Alliance Inventory-Short Form (WAI-SR), and the Group Climate Questionnaire-Short Form (GCQ-S). Participants who met inclusion criteria were identified by their enrollment in the Intensive Outpatient Program (IOP).

Immediately before the participants' first group psychotherapy session, the researcher met the participant and caregiver in the outpatient clinic waiting room and described the intent of the study. Once the adolescent participants and their parent or caregiver provided informed consent to participate in the study by signing the relevant forms, the researcher asked the parent or caregiver to complete a short demographic questionnaire. The researcher administered the URICA to the participants and their parent or caregiver to assess their stage of change beliefs. Immediately following the 
first, fourth, and seventh IOP group the researcher administered the adolescent participant the WAI-SR to assess the quality of the working alliance. The demographic questionnaire and the assessments took approximately 10 minutes to complete. The questionnaire and assessment measures were administered in the outpatient clinic waiting room.

Prior to the beginning of the fifteenth group psychotherapy session, adolescent participants and their parent or caregiver were administered the URICA by the researcher. Adolescent participants were administered the WAI-S after the fifteenth group psychotherapy session. Completed questionnaires and assessments were sealed and placed in secure files collected by the researcher.

Data Analysis. Table 3 outlines the current study's hypotheses, research questions, supplemental analyses, the measures used for assessment, and the statistical analyses employed. To address the hypothesis that the adolescent sample would rate the working alliance more positively over time, a profile analysis was utilized. The Working Alliance Inventory (WAI-SR) total scores were entered as dependent variables and participants' gender were entered as the grouping variable. To address the hypothesis that the adolescents' URICA subscale scores would change over time, an independent sample t-test was utilized. The URICA was administered to the adolescent sample at session one and session fifteen of group psychotherapy. The URICA score, utilizing the method employed by Emmerling and Whelton (2008) of grouping the patient into the five subscales of Precontemplation, Contemplation, Preparation, Action, and Maintenance was entered as the dependent variable. To address the hypothesis that the URICA score 
was related to the subscales of the WAI-SR (Goal, Task, and Bond) at session one and at session fifteen, a Pearson Product moment correlation was utilized. To address the hypothesis that the GCQ-S (Engaged) scores will improve over time between sessions one and fifteen, a profile analysis was utilized. The GCQ-S (Engaged) scores were entered as dependent variables and the participants' gender was entered as the grouping variable.

The research questions addressed in the study were intended to study the relationship between the adolescent sample and parent/caregiver sample, specifically whether there was a relationship between the parents' stage of change beliefs about their adolescents' "problem" behavior and their adolescent's stage of change beliefs about the "problem" behavior at session one of group psychotherapy and whether there was a relationship between the parents' stage of change beliefs about their adolescents' "problem" behavior and their adolescents' stage of change beliefs about the "problem" behavior at session fifteen of group psychotherapy.

Supplemental analyses were included to determine if a relationship existed between the variables of the working alliance and group cohesion scores. Also, it was predicted that adolescents would improve over the course of the group as measured by the Ohio Scales. This was included as a supplemental analysis. 
Table 3

Hypotheses and Research Questions for the Proposed Study

\begin{tabular}{|c|c|c|}
\hline Hypothesis & Measures Used & Statistical Test \\
\hline $\begin{array}{l}\text { 1. It is predicted that the } \\
\text { adolescent sample will rate } \\
\text { the working alliance more } \\
\text { positively over time, as } \\
\text { measured following sessions } \\
\text { one (Week 1), four (Week } \\
\text { 2), seven (Week 3), and } 15 \\
\text { (Week 5) of group } \\
\text { psychotherapy. }\end{array}$ & $\begin{array}{l}\text { WAI-SR total scores } \\
\text { measured after sessions } \\
\text { one, four, seven, and } 15 \text {. }\end{array}$ & Profile Analysis \\
\hline $\begin{array}{l}\text { 2. It is predicted that the } \\
\text { adolescent sample URICA } \\
\text { scores will progress to a } \\
\text { higher stage over time, as } \\
\text { measured prior to session } \\
\text { one and prior to session } 15 \\
\text { of group psychotherapy. }\end{array}$ & $\begin{array}{l}\text { URICA scores measured } \\
\text { prior to session one and } \\
\text { session } 15 .\end{array}$ & Paired-samples t-test \\
\hline $\begin{array}{l}\text { 3. In the adolescent sample, } \\
\text { there will be a significant } \\
\text { relationship between the } \\
\text { URICA score and the } \\
\text { subscales of the WAI-SR } \\
\text { (Goal, Task, and Bond) and } \\
\text { Total score measured at } \\
\text { session one and session } 15 \text {. }\end{array}$ & $\begin{array}{l}\text { URICA scores measured } \\
\text { prior to session one and } \\
\text { session } 15 . \\
\text { WAI-SR subscale scores } \\
\text { measured after sessions one } \\
\text { and } 15 \text {. }\end{array}$ & $\begin{array}{l}\text { Pearson product moment } \\
\text { correlation }\end{array}$ \\
\hline $\begin{array}{l}\text { 4. In the adolescent sample, } \\
\text { there will be more positive } \\
\text { ratings of the group } \\
\text { cohesion as measured }\end{array}$ & $\begin{array}{l}\text { GCQ-R (Engaged) subscale } \\
\text { scores after sessions one, } \\
\text { four, seven, and } 15 .\end{array}$ & Profile Analysis \\
\hline
\end{tabular}




\begin{tabular}{|c|c|c|}
\hline $\begin{array}{l}\text { following sessions one } \\
\text { (Week 1), four (Week 2), } \\
\text { seven (Week 3), and } 15 \\
\text { (Week 5) of group } \\
\text { psychotherapy. }\end{array}$ & & \\
\hline Research Questions & Measures Used & Statistical Tests \\
\hline $\begin{array}{l}\text { 1. Is there a relationship } \\
\text { between the parents' stage } \\
\text { of change beliefs about their } \\
\text { adolescents' problem } \\
\text { behavior and their } \\
\text { adolescents' stage of change } \\
\text { beliefs prior to session one } \\
\text { of group psychotherapy and } \\
\text { session } 15 \text { of group } \\
\text { psychotherapy? }\end{array}$ & $\begin{array}{l}\text { Parents' URICA scores } \\
\text { measured prior to session } \\
\text { one and session } 15 \\
\text { Adolescents' URICA } \\
\text { subscale scores measured } \\
\text { prior to session one and } \\
\text { session } 15\end{array}$ & $\begin{array}{l}\text { Pearson product moment } \\
\text { correlation }\end{array}$ \\
\hline Supplemental Analyses & Measures Used & Statistical Tests \\
\hline $\begin{array}{l}\text { 1. It is predicted that the } \\
\text { adolescent ratings for the } \\
\text { Ohio Scales (Problem } \\
\text { Severity, Hopefulness, and } \\
\text { Functioning) will improve } \\
\text { from session one to session } \\
15 \text { of group psychotherapy. }\end{array}$ & $\begin{array}{l}\text { Adolescents' Ohio Scale } \\
\text { scores measured prior to } \\
\text { session one and } 15 .\end{array}$ & Paired-samples t-tests \\
\hline $\begin{array}{l}\text { Is there a relationship } \\
\text { between adolescent working } \\
\text { alliance ratings and group } \\
\text { cohesion ratings from } \\
\text { session one to session } \\
\text { fifteen of group } \\
\text { psychotherapy? }\end{array}$ & $\begin{array}{l}\text { Working alliance ratings } \\
\text { (WAI-SR) and group } \\
\text { cohesion ratings (GCQ-S- } \\
\text { Engaged) at sessions one, } \\
\text { four, seven, and fifteen. }\end{array}$ & $\begin{array}{l}\text { Pearson product moment } \\
\text { correlation }\end{array}$ \\
\hline
\end{tabular}




\section{Chapter Summary}

In order to capture the changes in the adolescents' ratings of working alliance over time and URICA subscale ratings over time, the current study employed a quantitative research approach. Methods of data collection, including identifying research participants, informed consent, and instruments to be used were discussed. Data were collected through demographic questionnaires and the GCQ-S, WAI-SR and URICA assessment measures. The data was analyzed using profile analysis, independent and paired sample t-tests, and Pearson product moment correlation. The next chapter is devoted to a presentation of the analyses conducted in the study. 


\section{Chapter 4}

\section{RESULTS}

This chapter presents the results of statistical analyses associated with this study. The preliminary results are outlined, followed by the primary analyses that relate to the four hypotheses and two research questions. Results of follow-up analyses are also

presented. All statistical analyses were performed with the use of the Statistical Package for the Social Science version 19. Alpha levels were set at .05 for all analyses. The size of correlation coefficients was considered small if $r$ was .20 to .39 , moderate if $r$ was .40 to .69 , large if $r$ was .70 to .89 , and very large if $r$ was .90 to 1 (Cohen, 1988). To determine the strength of eta squared values or effect size, Cohen's (1988) guidelines were used: small effect size $=.01$, moderate effect size $=.06$ and large effect size $=.14$.

\section{Preliminary Analyses}

This section includes information on the reliability of measures utilized in this study, an analysis of how missing data were managed, and a comparison of study variables to determine how gender, age, or previous treatment impacted the data. Reliability of Measures. Reliability of the study measures was calculated to ensure internal consistency and to assess the degree to which the measures functioned similarly to those in the norming samples. Cronbach's alpha for the study's measures were: .88 for the GCQ-S, .97 for the WAI-SR, and .70 for the URICA. Cicchetti (1994) 
suggested guidelines for reliability estimates in clinical samples: $r<.70$ (unacceptable), $r$ $<.80$ (fair), $\mathrm{r}<.90$ (good), and $\mathrm{r}>.90$ (excellent). The WAI-SR produced "excellent" internal consistency for this study and the GCQ-S reliability estimate is consistent with previous research (.88 to .94) and can be stated as "good" based on Cichetti's (1994) guidelines. The URICA produced lower internal reliability estimates at .70 in this study. In Cohen et al.'s (2005) study with adolescents, the reliability coefficients for the individual URICA subscales were found to be "unacceptable" for Precontemplation, "fair" for the Maintenance subscale, and "good" for both Contemplation and Action based on Cichetti's (1994) suggestions. Cohen et al. (2005) suggested interpreting their results on the Precontemplation scale with caution due to the low level of internal consistency. Similarly, the current study's URICA subscale results should be interpreted with caution. Overall, it can be assumed that the reliability measures for this study were similar to those for the samples used to norm the data with the exception of the URICA. Analysis of Missing Data. There were twenty participants completing the IOP group and the majority of assessment measures and a total of fifteen participants completing the group and all assessment measures. The assessment measures screened for missing data included the demographic questionnaires, the Ohio Scales, WAI-SR, GCQ-S, and the URICA. The data set was examined for missing data to understand patterns contributing to the missing data. Within the assessment measures, there were no missing items or multiple responses provided.

Upon inspection of the twenty participants' data, there was a systematic pattern to the missing data. This was due to participants' termination from the group, attrition, or 
failure to complete the needed assessment measures. Missing data occurred most often at session fifteen, or the final group IOP session and the complete data for that session was missing including the WAI-SR, the GCQ-S, and the URICA. When missing data occurred at session fifteen, those participants' data were not utilized in analyses that compared session one data to session fifteen data. For the purposes of the analysis, missing data were excluded pairwise. Pairwise exclusion of data allowed for analysis of variables that had missing data rather than deleting them from the analysis altogether.

Missing data occurred when participants terminated prematurely from the IOP group, were not present for the final group session, or failed to complete the assessment measures at the final group session. Explanations for this include the fact that several participants failed to attend their last IOP session. Also, at times the researcher was not present for the final IOP session to ensure all participants completed the necessary measures. When the researcher could not be present to collect the measures in person, a reminder phone call was made to the participants on the day of their last session and they were asked to place completed measures in a secure mailbox at the site for the researcher to pick up. If the participants did not complete the measures at the final session, the researcher contacted them by phone and sent the measures by mail with stamped return envelopes included in an effort to gather complete data.

Completed Participants Compared to Dropout Participants. Twenty five participants consented to the study and began the IOP group. Five of these participants dropped out after completing only one session of IOP. From these five participants, three GCQ-S and WAI-SR measures and five URICA measures were collected. The data 
for these five dropout participants were examined and compared to the study completers' data at session one to determine if differences existed or if reasons for their dropout could be identified. Descriptive statistics for the three adolescents who dropped out of the study demonstrated negligible differences on the GCQ-S $(\mathrm{M}=3.33, \mathrm{SD}=1.53 ; \mathrm{M}=$ $3.40, \mathrm{SD}=1.2$, respectively). Of the dropout participants, stage of change beliefs consisted of three Contemplation ratings, one Precontemplation, and one Action rating. This was similar to study completers' stage of change beliefs at session one in that most rated themselves to be in Contemplation. An independent-samples t-test was conducted to compare the working alliance ratings for the 20 study completers and the three study dropouts. There was a significant difference in working alliance scores for dropouts (M $=2.70 ; \mathrm{SD}=.75)$ and study completers $[\mathrm{M}=3.88, \mathrm{SD}=.73 ; \mathrm{t}(21)=-2.62, p=.016]$. The magnitude of the difference in the means was very large (eta squared $=.25$ ). See Table 4 for the means and standard deviations on main assessment measures for the participants who terminated early and the twenty participants who completed the IOP group.

Table 4

Means and Standard Deviations for Dropout Participants and Study Completers on Main Assessment Measures

\begin{tabular}{|l|l|l|l|}
\hline $\begin{array}{l}\text { Dropout Participants } \\
\text { (for Session One) }\end{array}$ & N & Mean & Standard Deviation \\
\hline WAI-SR Total & 3 & 2.70 & .75 \\
\hline GCQ-S (Engaged) & 3 & 3.33 & 1.53 \\
\hline URICA & 5 & $\begin{array}{l}3.0 \\
\text { (Contemplation) }\end{array}$ & 5.07 \\
\hline $\begin{array}{l}\text { Study Completers } \\
\text { (for Session One) }\end{array}$ & $\mathrm{N}$ & Mean & Standard Deviation \\
\hline WAI-SR Total & 20 & 3.88 & .73 \\
\hline GCQ-S (Engaged) & 20 & 3.40 & 1.2 \\
\hline URICA & 20 & $\begin{array}{l}2.95 \\
\text { (Contemplation) }\end{array}$ & 1.19 \\
\hline
\end{tabular}


Mean Comparisons by Gender. To determine if there were any gender differences, independent sample t-tests were conducted to compare the scores for male and female adolescent participants on the primary study variables. A total of fifteen participants completed the WAI-SR and GCQ-S after session one, four, seven, and fifteen and the URICA at sessions one and fifteen. To analyze potential gender differences on the working alliance measure, the WAI-SR, an independent t-test was conducted. Levene's Test for Equality of Variances indicated that equal variances could be assumed for WAI-SR subscale and Total scores across all four sessions. There was no significant difference in scores for males $(\mathrm{M}=4.16, \mathrm{SD}=.786)$ and females, $[\mathrm{M}=4.28, \mathrm{SD}=.556 ; \mathrm{t}(13)$ $=-.26, p=.80]$ for the WAI-SR subscale and Total scores.

To assess potential gender differences of participants' group cohesion ratings, independent sample t-tests were conducted on the cohesion subscale of the GCQ-S. Levene's Test for Equality of Variances indicated that equal variances could be assumed for the GCQ-S scores across sessions one through fifteen. There was no significant difference in scores for males $(\mathrm{M}=3.82, \mathrm{SD}=1.25)$ and females $[\mathrm{M}=4.25, \mathrm{SD}=.957 ; \mathrm{t}(13)$ $=.34, p=.74]$ for the GCQ-S.

To investigate gender differences on the stages of change measure, the URICA, an independent t-test was conducted. Levene's Test for Equality of Variances indicated that equal variances could be assumed for the URICA adolescent scores across sessions one through fifteen. There was no significant difference in scores for males $(M=3.36$, $\mathrm{SD}=1.03$ ) and females $[\mathrm{M}=2.75, \mathrm{SD}=1.50 ; \mathrm{t}(13)=.911, p=.38]$ for the URICA. Due to the fact that no significant gender differences existed on the major study variables, their 
results were combined for the remaining analyses, except when utilized as the grouping variable for profile analysis of WAI-SR and GCQ-S scores.

\section{Primary Analyses}

\section{Statistical Analyses Addressing Hypotheses}

This section includes the results of the primary analyses related to the four hypotheses. Results of follow-up analyses that were conducted to explore other related findings based on the primary analyses are also presented.

Hypothesis 1. The first hypothesis predicted that the adolescent participants' would rate the working alliance more positively over time. To examine the adolescent ratings of the working alliance, the Working Alliance Inventory-Short Form (WAI-SR) was administered following sessions one (Week one), four (Week two), seven (Week three), and fifteen (Week five) of the IOP group. There were fifteen participants who completed WAI-SR assessments at session one, session four, session seven, and session fifteen. The resulting data were analyzed using a profile analysis. Gender was utilized as the grouping variable. Using descriptive analyses and scatterplots in SPSS for Windows (Version 19), no univariate or multivariate outliers were detected amongst the participants. Assumptions regarding normality of sampling distributions, homogeneity of variance-covariance matrices, linearity, and multicollinearity were met.

A $p<.05$ level was set for the study there was not a statistically significant effect found for time $[F(3,11)=2.31, p=.091$, partial eta squared $=.151]$. No statistically significant effects were found for gender $[F(3,11)=.343, p=.794$, partial eta squared $=$ $.026]$ or the gender by time interaction $[\mathrm{F}(3,11)=.003, \mathrm{p}=.954$, partial eta squared $=.00]$ 
(See Table 4). However, WAI-SR ratings increased from session one to session fifteen. While the gender differences in working alliance ratings did not differ significantly, male participants' ratings increased steadily across the group while females demonstrated a decrease in WAI-SR ratings at session two and increased alliance ratings over the last two data points. The mean WAI-SR ratings and standard deviations are presented in Table 4 for male and female participants. See Figure 1 for a graph of the fifteen male and female participants' WAI-SR ratings. Hypothesis 1 was not supported in that the differences in working alliance ratings were not statistically significant from session one to session fifteen. Participants did rate the working alliance more positively over time. Post-hoc $\mathrm{G}^{*}$ power analysis determined that with a sample size of 15 , correlations at .1, the assumed power for this study was .80 . In order to achieve an assumed power of .90 , with response patterns, 20 participants would be needed. Thus, the effect size for this analysis was considered large (Cohen, 1988).

Table 5

Descriptive Statistics for Male and Female Participants' WAI-SR Total scores for Session 1, Session 4, Session 7, and Session 15

\begin{tabular}{|l|l|l|l|}
\hline Time Period & N & Mean & Standard Deviation \\
\hline Session 1 Males & 11 & 3.83 & 0.84 \\
\hline Session 1 Females & 4 & 3.86 & 0.80 \\
\hline Session 4 Males & 11 & 3.92 & 0.74 \\
\hline Session 4 Females & 4 & 3.70 & 1.21 \\
\hline Session 7 Males & 11 & 3.95 & 0.83 \\
\hline Session 7 Females & 4 & 3.93 & 0.83 \\
\hline Session 15 Males & 11 & 4.16 & 0.79 \\
\hline Session 15 Females & 4 & 4.28 & 0.56 \\
\hline
\end{tabular}


Table 6

Main Effects of Time, Gender, and Gender by Time Interaction for WAI-SR Total Scores for Session 1, Session 4, Session 7, and Session 15

Test of Within-Subjects Effects

\begin{tabular}{|l|l|l|l|l|l|}
\hline Source & Df & $\begin{array}{l}\text { Mean } \\
\text { Square }\end{array}$ & F & Sig. & Partial Eta Squared \\
\hline Time & 3 & .401 & 2.313 & .091 & .151 \\
\hline Time*Gender & 3 & .059 & .343 & .794 & .026 \\
\hline Error (Factor 1) & 39 & .173 & & & \\
\hline
\end{tabular}

Test of Between-Subjects Effects

\begin{tabular}{|l|l|l|l|l|l|}
\hline Source & Df & $\begin{array}{l}\text { Mean } \\
\text { Square }\end{array}$ & F & Sig. & Partial Eta Squared \\
\hline Gender & 1 & .008 & .003 & .954 & .000 \\
\hline Error & 13 & 2.171 & & & \\
\hline
\end{tabular}

Figure 1

Profile Analysis of WAI-SR Total Scores by Gender for Sessions One, Four, Seven, and Fifteen $(n=15)$

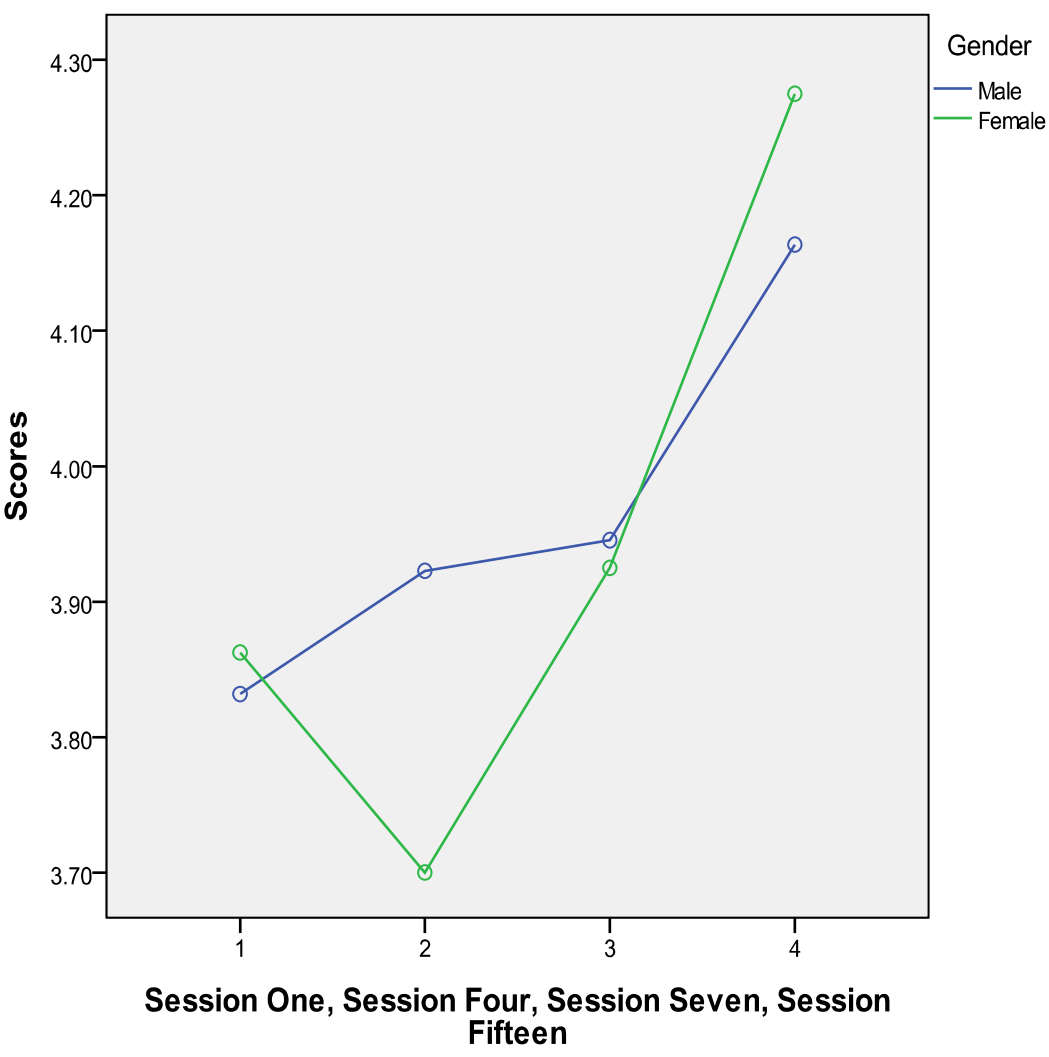


Hypothesis 2. The second hypothesis predicted the adolescent participants' URICA profile score would progress to a higher stage over time. The URICA was administered to the participants at the initial IOP group session (Week one) and again at the final group session (Week five) of IOP. The URICA is a 32-item Likert scale measure with scores ranging from one (disagree) to five (strongly agree). There are several methods of interpreting scores from the URICA, including factor analysis with large sample sizes, adding the contemplation, action, and maintenance scores together and subtracting the total from the precontemplation scores to obtain a "readiness to change score", and assigning participants to one of the five stages of change based on their highest subscale score (Cohen et al., 2005; Emmerling \& Whelton, 2008; Prochaska, 1992). The latter method was chosen for this study due to the small sample size and based on previous research with the URICA measure to support a fifth stage, Preparation, as an interim stage between contemplation and action (Prochaska \& Prochaska, 2004). This method has been endorsed by Emmerling and Whelton (2008) who utilized the same method in their study. To obtain the subscale scores, separate averages were calculated by totaling the appropriate items and dividing the total by eight, the total number of items in each subscale. If identical scores were obtained in the contemplation and action subscales, the participant was assigned to the preparation stage based on research by Prochaska et al. (1992). Prochaska and Prochaska (2004) stated that high scores on the URICA for both contemplation and action suggested the individual would fall into the Preparation stage of change. 
To examine the difference between participants' URICA scores at session one (Week one) and session 15 (Week five), a paired samples t-test was computed. There were fifteen participants $(n=15)$ who completed the URICA at session one and session fifteen. There was no statistically significant difference in URICA scores from Time 1 $(\mathrm{M}=3.0, \mathrm{SD}=1.20)$ to Time $2[\mathrm{M}=3.2, \mathrm{SD}=1.15, t(14)=-.435, p=.67]$. The eta squared statistic (.01) indicated a small effect size. Of the fifteen participants that completed the URICA at session one and session fifteen, six participants demonstrated movement in stage of change ratings from the beginning of the group to the end in a positive direction such as movement from precontemplation to action. Six participants did not demonstrate any movement in stage of change ratings between session one and session fifteen, and three participants reported movement from a higher stage of change such as maintenance to a lower stage of change such as precontemplation. There was substantial variability in the participants' stage of change ratings both at session one and session fifteen. Hypothesis 2 was not supported.

Hypothesis 3. The third hypothesis predicted that there would be a significant relationship between URICA scores measured at session one and the Total WAI-SR scores as well as the three subscales of the WAI-SR (Goals, Task, Bond) measured at session one. There were twenty participants who completed the URICA and the WAI-SR measures at session one. To examine the relationship between the URICA scores at session one and the Goal, Task, Bond and Total subscales of the WAI-SR at session one, Pearson product-moment correlation coefficients were computed. Preliminary analyses were performed to ensure no violation of the assumptions of normality or linearity. 
There were no statistically significant correlations for the Goal subscale of the WAI-SR and the URICA score measured at session one, $[r=-.15, n=20, p=.54]$, the Task subscale of the WAI-SR $[r=.06, n=20, p=.79]$, the Bond subscale $[r=.02, n=$ 20, $p=.92]$, or the Total WAI-SR and URICA score $[r=-.03, n=20, p=.91]$.

Participants' stage of change beliefs were not related to their working alliance ratings at the outset of the group. See Table 7 for the correlations for Hypothesis Three related to WAI-SR subscale scores and URICA scores measured at session one.

Table 7

Pearson Product-Moment Correlations between WAI-SR Subscale Scores and URICA at Session One

\begin{tabular}{lccccc}
\hline Measures & 1 & 2 & 3 & 4 & 5 \\
(1) URICA Session 1 & -- & -.03 & -.15 & .06 & .02 \\
(2) WAI-SR Total & -.03 & -- & .90 & .88 & .75 \\
(3) WAI-SR Goal & -.15 & .90 & -- & .83 & .44 \\
(4) WAI-SR Task & .06 & .87 & .83 & -- & .45 \\
(5) WAI-SR Bond & .02 & .75 & .44 & .45 & -- \\
\hline
\end{tabular}

The third hypothesis also predicted there would be a significant relationship between the URICA score measured at session fifteen and Total and subscale scores of the WAI-SR (Goals, Task, Bond). There were fifteen participants who completed the URICA and the WAI-SR measures at session fifteen. To examine the relationship between URICA scores and the subscales of the WAI-SR, Pearson product-moment correlation coefficients were computed. There was no correlation between the Goals subscale of the WAI-SR and the URICA score measured at session fifteen $[r=-.05, n=$ $15, p=.87]$, the Task subscale $[r=-.10, n=15, p=.71]$, the Bond subscale $[r=.14, n=15$, $p=.63]$, and the Total WAI-SR score measured at session fifteen $[r=-.02, n=15, p=.96]$. 
See Table 8 for a summary of the correlations in Hypothesis 3 related to participants WAI-SR subscale and Total scores and URICA scores measured at session fifteen. Overall, participants' scores on the URICA measured at session 15 did not show a relationship between the Goals, Task, Bond or Total subscales of the WAI-SR measured at session 15. In other words, the participants' readiness to change was not correlated with their working alliance ratings at the end of the group. Hypothesis 3 was not supported.

Table 8

Pearson Product-Moment Correlations between WAI-SR Subscale Scores and URICA at Session Fifteen

\begin{tabular}{lccccc}
\hline Measures & 1 & 2 & 3 & 4 & 5 \\
(1) URICA Session 15 & -- & -.02 & -.05 & -.10 & .14 \\
(2) WAI-SR Total & -.02 & -- & .95 & .90 & .77 \\
(3) WAI-SR Goal & -.05 & .95 & -- & .81 & .69 \\
(4) WAI-SR Task & -.10 & .90 & .81 & -- & .46 \\
(5) WAI-SR Bond & .14 & .77 & .69 & .46 & -- \\
\hline
\end{tabular}

Hypothesis 4. The fourth hypothesis predicted the adolescent participants would provide more positive ratings of group cohesion over time as measured by the GCQ-S (Engaged) subscale. The statistical significance of differences over time was computed using a profile analysis for the fifteen participants who completed the assessment measures at the last session. Profile analysis was conducted to compare male and female participants' scores on the GCQ-S (Engaged) subscale following sessions one, four, seven, and fifteen. No univariate or multivariate outliers were detected amongst the participants. Assumptions regarding normality of sampling distributions, homogeneity of 
variance-covariance matrices, linearity, and multicollinearity were met. The means and standard deviations for male and female participants are presented in Table 9.

At the $p<.05$ level set for the study, there was not a statistically significant effect found for time $[F(3,11)=1.08, p=.37$, partial eta squared $=.077]$. No statistically significant effects were found for gender $[F(3,11)=1.71, p=.18$, partial eta squared $=$ $.117]$, or the gender by time interaction $[\mathrm{F}(3,11)=.001, p=.98$, partial eta squared $=.00]$ (See Table 10). See Figure 2 for a graph of the male and female participants' GCQ-S (Engaged) ratings. The male participants displayed more positive ratings of group cohesion over time, with the highest group cohesion ratings after Session seven (Week

3). When taken together the participants rated group cohesion more positively over time, but differences were not statistically significant. Hypothesis four was not supported.

Table 9

Descriptive Statistics for Male and Female Participants GCQ-S (Engaged) Subscale for Session 1, Session 4, Session 7, and Session 15

\begin{tabular}{|l|l|l|l|}
\hline Time Period & N & Mean & Standard Deviation \\
\hline Session 1 Males & 11 & 3.45 & 1.37 \\
\hline Session 1 Females & 4 & 3.50 & 1.29 \\
\hline Session 4 Males & 11 & 3.63 & 1.20 \\
\hline Session 4 Females & 4 & 4.50 & .577 \\
\hline Session 7 Males & 11 & 3.91 & 1.30 \\
\hline Session 7 Females & 4 & 3.25 & 1.26 \\
\hline Session 15 Males & 11 & 3.81 & 1.68 \\
\hline Session 15 Females & 4 & 3.50 & 2.52 \\
\hline
\end{tabular}

Table 10

Main Effects for Time and Gender and Gender by Time Interaction for GCQ-S Test of Within-Subjects Effects

\begin{tabular}{|l|l|l|l|l|l|}
\hline Source & Df & $\begin{array}{l}\text { Mean } \\
\text { Square }\end{array}$ & F & Sig. & Partial Eta Squared \\
\hline Time & 3 & .787 & 1.078 & .370 & .077 \\
\hline Time*Gender & 3 & 1.254 & 1.718 & .179 & .117 \\
\hline Error (Factor 1) & 39 & .730 & & & \\
\hline
\end{tabular}


Test of Between-Subjects Effects

\begin{tabular}{|l|l|l|l|l|l|}
\hline Source & Df & $\begin{array}{l}\text { Mean } \\
\text { Square }\end{array}$ & F & Sig. & Partial Eta Squared \\
\hline Gender & 1 & .003 & .001 & .980 & .000 \\
\hline Error & 13 & 5.007 & & & \\
\hline
\end{tabular}

Figure 2

Profile Analysis of GCQ-S (Engaged) Subscale Scores by Gender from Sessions One to Fifteen

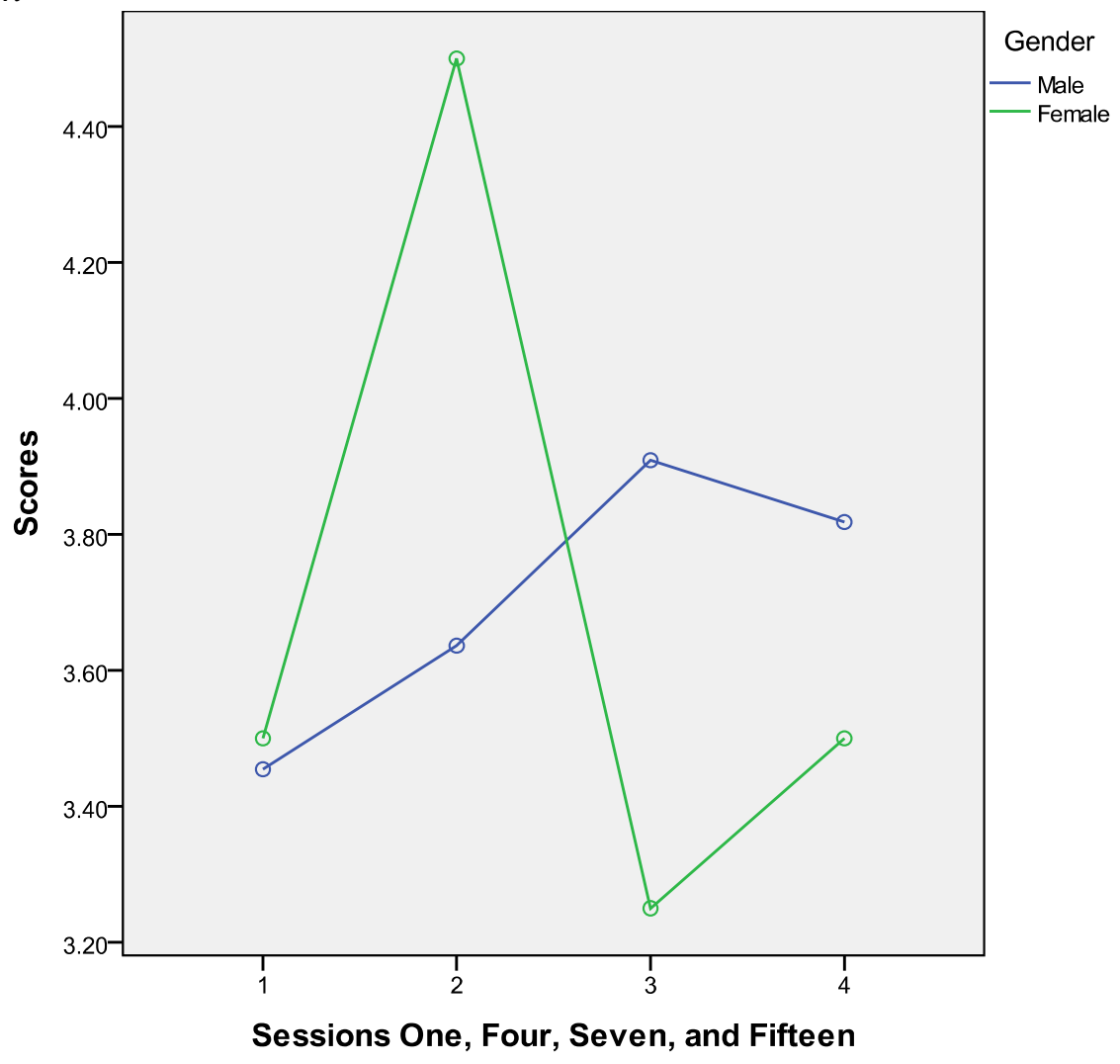

\section{Statistical Analyses Addressing Research Questions}

Research Question 1. The first research question addressed whether a relationship existed between the parents' stage of change beliefs about their adolescents' problem behavior and the adolescents' stage of change beliefs prior to beginning the IOP group. The relationship between the parents' stage of change beliefs (as measured by the URICA-Parent) and the adolescents' stage of change beliefs (as measured by the URICA- 
Adolescent) was investigated using Pearson product-moment correlation coefficient. Preliminary analyses were performed to ensure no violation of the assumptions of normality and linearity. There was no significant correlation between the two variables $[r$ $=.18, n=20, p=.45]$. This may have been due to the way in which the URICA was administered, by asking participants to write in the "problem" they were addressing in psychotherapy. Several of the adolescent/parent dyads had similar responses for the problem behavior, including depression, difficulty communicating with others, or recent release from inpatient hospitalization. However, many of the adolescent/parent dyads differed dramatically in their responses to the problem behavior on the URICA. One adolescent wrote "I am getting in trouble at school all the time" while his parent wrote "he had a suicide attempt." This discrepancy contributed to the lack of significant relationship between the parents' stage of change beliefs about their adolescents' problem behaviors and the adolescents' stage of change beliefs prior to beginning the IOP group.

Research Question 2. The second research question addressed whether a relationship existed between the parents' stage of change beliefs about their adolescents' problem behavior and the adolescents' stage of change beliefs at the conclusion of the IOP group. The relationship between the parents' stage of change beliefs (as measured by the URICA-Parent) and the adolescents' stage of change beliefs (as measured by the URICA-Adolescent) was investigated using a Pearson product-moment correlation coefficient. Preliminary analyses were performed to ensure no violation of the assumptions of normality and linearity. There was no correlation between the two variables $[r=-.01, n=20, p=.97$.]. Similarly to the issue encountered with the first 
research question, the adolescent/parent dyads described different problem behaviors than in the first administration of the URICA or had a high amount of variability in the responses that affected the relationship between the parents' stage of change beliefs about their adolescents' problem behavior and the adolescents' stage of change beliefs at the conclusion of the IOP group.

\section{Supplemental Analyses}

Additional analyses were conducted to further examine relationships between the various assessment measures such as the working alliance ratings and group cohesion ratings. Participants' previous mental health treatment was compared to their initial stage of change ratings to determine if previous treatment had any bearing on their motivation to change behavior. The Ohio Scales were examined as an outcome measure for the study to determine changes in participants' ratings of problem severity, hopelessness, and functioning (Ogles et al., 2001). These supplemental analyses were conducted to better understand how the current study may relate to previous research.

\section{Differences on the Ohio Scales over Time}

The Ohio Youth Problems, Functioning, and Satisfaction Scale (Ohio Scales) were developed to be multi-source measures of outcome for children and adolescents receiving mental health services (Ogles et al., 2001). The Ohio Scales have three rating forms, parent, teacher/therapist, and self-report. The Ohio Scales were administered to each participant before every IOP group session by the IOP coordinator. The parent/caregiver and the adolescent were asked to complete the measure and turn it in to the IOP therapists or the clerical staff after group. The Ohio scales were intended to 
assess ongoing progress and serve as an outcome measure of adolescents. For the purposes of this study, the Ohio Scales data from the adolescent participants were utilized to measure participants' progress at the beginning of the IOP group and at the end of the group, thus data from session one and session 15 were utilized.

To examine the relationship between the participants' Ohio Scales scores at session one and their scores at session 15, paired samples t-tests were computed. Paired samples t-tests were conducted to evaluate the impact of the IOP group on participants' self-ratings of Problem Severity, Hopefulness, and Functioning. There was a statistically significant decrease in Problem Severity ratings from Session one $(M=23.88, S D=$ 16.12) to Session fifteen $[M=17.12, S D=13.52, t(16)=2.25, p=.04]$. The eta squared statistic (.24) indicated a large effect size. There was not a statistically significant decrease in Hopefulness ratings from Session one $(M=9.0, S D=5.61)$ to Session $15[M$ $=8.29, S D=4.81, t(16)=.502, p=.62]$. The eta squared statistic (.02) indicated a small effect size. There was a statistically significant increase in Functioning ratings from Session one $(M=44.65, S D=14.75)$ to Session fifteen $[M=53.41, S D=12.48, t(16)=-$ 2.53, $p=.02]$. The eta squared statistic (.29) indicated a large effect size. This suggests that participants improved in functioning and ratings of problem severity over the course of the study.

\section{GCQ-S (Engaged) Subscale and WAI-SR Total Scores}

Previous research on the working alliance and group cohesion has found some relationship between these constructs (Johnson et al., 2005; Marziali et al., 1997). To determine if this study would demonstrate a similar relationship, Pearson product- 
moment correlations were used to compare adolescent ratings on the GCQ-S (Engaged) subscale and the WAI-SR Total scores across sessions one (Week one), four (Week two), seven (Week three), and fifteen (Week five). An alpha level of .05 was utilized. There was no correlation between the two variables of GCQ-S (Engaged) at session one and WAI-SR Total at session one, $[r=.25, n=20, p=.28]$. There was a not a significant correlation between the two variables of GCQ-S (Engaged) at session four and WAI-SR Total at session four $[r=.40, n=20, p=.08]$. There was a large, positive correlation between the variables of GCQ-S (Engaged) at session seven and WAI-SR Total at session seven, [ $r=.67, n=19, p=.002]$, with higher Engaged subscale scores associated with higher WAI-SR Total scores. There was a large, positive correlation between the variables of GCQ-S (Engaged) at session fifteen and WAI-SR Total at session fifteen, $[r$ $=.67, n=15, p=.01]$, with higher Engaged subscale scores associated with higher WAISR Total scores. This suggests that a relationship exists between the WAI-SR, which measures working alliance development, and the GCQ-S, which measures group climate and cohesion. As scores increased on the working alliance measure they also increased on ratings of group cohesion. See Table 11 for a summary of the correlations related to GCQ-S (Engaged) scores and WAI-SR Total scores. 
Table 11

Pearson Product-Moment Correlations between GCQ-S (Engaged) scores and WAI-SR Total Scores at Session One, Four, Seven, and Fifteen

*Asterisks indicate positive correlations between the variables

\begin{tabular}{|l|l|l|l|l|}
\hline & $\begin{array}{l}\text { GCQ-S (E) } \\
\text { One }\end{array}$ & $\begin{array}{l}\text { GCQ-S (E) } \\
\text { Two }\end{array}$ & $\begin{array}{l}\text { GCQ-S (E) } \\
\text { Three }\end{array}$ & $\begin{array}{l}\text { GCQ-S (E) } \\
\text { Four }\end{array}$ \\
\hline WAI-SR (Total) One & $\begin{array}{l}r=.25, \\
p=.28\end{array}$ & & & \\
\hline WAI-SR (Total) Two & & $\begin{array}{l}r=.40, \\
p=.08\end{array}$ & & \\
\hline $\begin{array}{l}\text { WAI-SR (Total) } \\
\text { Three }\end{array}$ & & & $\begin{array}{l}r=.67^{*}, \\
p=.002\end{array}$ & \\
\hline $\begin{array}{l}\text { WAI-SR (Total) } \\
\text { Four }\end{array}$ & & & & $\begin{array}{l}r=.67^{*}, \\
p=.01\end{array}$ \\
\hline
\end{tabular}

Impact of Previous Mental Health Treatment on Stage of Change Ratings

Fitzpatrick and Irannejads' (2008) sample of adolescents consisted of clients who had long relationships with their counselors prior to the study. These adolescents had higher Action scores and stronger alliance ratings than the adolescents with Precontemplation scores. These researchers suggested that alliance ratings would be highest when the adolescent presented to therapy in the Action stage of change. However, their study did not include data on participants who had not had prior mental health treatment. In this study, there were twenty participants who completed the demographic questionnaire, with 13 adolescents reporting previous mental health treatment and six reporting the IOP group as their first mental health treatment.

Due to a larger number of this study's participants having had previous mental health treatment, a supplemental analysis was conducted to determine how participants who had undergone previous treatment would rate their stage of change compared to participants who were just beginning treatment at session one of the IOP group. Visual 
inspection of the data and descriptive analyses showed that participants who had previous mental health treatment rated Precontemplation on the URICA while participants beginning mental health treatment rated their stage of change as Preparation or Action.

\section{Chapter Summary}

Chapter Four provided the results of the preliminary analyses, primary analyses, and supplemental analyses conducted for this study. The presentation of primary analyses included results from statistical tests performed to address the four research hypotheses and two research questions. Profile analysis trends for the working alliance and group cohesion ratings were explored as were relationships between URICA scores and WAI-SR subscale scores.

Working alliance ratings increased over time for both male and female participants but there was not a statistically significant main effect for time, gender or interaction. Overall, the mean URICA score placed participants in Preparation but paired-sample t-tests did not show statistically significant differences between URICA scores from session one to session fifteen based on participant rating. Correlation coefficients on the Goal, Task, Bond subscales of the WAI-SR were not associated with URICA scores at session one and session fifteen. Profile analysis showed that group cohesion ratings on the GCQ-S (Engaged) subscale were more positive over time but did not show a statistically significant effect for gender, time, or interaction. There was not a significant relationship between adolescent ratings of stage of change and parent ratings at session one or session fifteen. 
The supplemental analyses determined that participants improved over the course of the IOP group based on the Ohio Scale problem severity and overall functioning ratings. Correlation coefficients examining the relationship between the group cohesion ratings and the working alliance ratings demonstrated significant positive correlations at session seven and session fifteen. This indicated that as cohesion ratings increased, working alliance ratings increased. Previous mental health treatment did not predict higher stage of change ratings at session one compared to no previous treatment. In fact, participants who had previous treatment rated their stage of change beliefs lower than those who had no prior therapy experience. Chapter 5 further discusses these analyses, results, and their implications. Limitations of the results are outlined and recommendations for future research are described. 


\section{Chapter Five}

\section{DISCUSSION}

This study is the first to investigate the relationship between adolescents' stage of change beliefs and working alliance development in a group psychotherapy format. The concepts of stage of change beliefs and working alliance were examined by assessing the adolescents' beliefs and expectations about psychotherapy and relating these to the quality of the relationship between the adolescent clients and their therapist during an intensive outpatient group. Because this study gathered data in a group psychotherapy intervention, group cohesion was investigated as well as participants' overall symptom improvement and functioning during the course of the group.

This study had a small sample size and low reliability coefficient for one of the main assessment measures. These limitations make generalizing the findings problematic. Overall this study offers implications for future research and highlights the need for continued research with adolescents in order to identify the specific variables contributing to process and outcome in psychotherapy. Finding ways of tailoring interventions for this population may improve engagement and decrease attrition, both of which exist as difficulties for adolescents in psychotherapy. The important findings from this study are highlighted below. 
Specific Findings and Implications

In this study, although not specific hypotheses, adolescents' symptom severity ratings decreased and overall functioning ratings improved over the five-week IOP group treatment. This finding is consistent with previous research on the efficacy of group treatment with adolescents compared to control groups (Hoag \& Burlingame, 1997). The effect sizes for symptom severity and overall functioning were large for this study (.24 and .29 respectively) which has implications for clinical practice and teaching about the efficacy of brief, manualized group treatment for adolescents. Another important finding in this study relates to working alliance and group cohesion. Working alliance ratings were correlated with group cohesion ratings during the latter half of the group, concurring with Johnson et al.'s (2005) findings that in adult groups, group climate, cohesion, and alliance may be related but cannot be fully explained by one overarching construct. For adolescents in this study, the working alliance may have been linked to the level of cohesiveness they perceived in the group. This finding has implications for group leadership, suggesting the importance of the selection process and the need to develop cohesiveness as early as possible in a group setting.

This study did not find significant differences in working alliance ratings from the beginning to end of the group. Despite these nonsignificant findings, previous research suggests that working alliance does get stronger over time (Shirk \& Karver, 2008). This study's nonsignificant findings may well be based on the small sample size. More research is needed on working alliance with adolescents to determine if it develops in a 
similar pattern to adults (Creed \& Kendall, 2005; Hogue et al., 2006; Horvath \& Symonds, 1991; Smith \& Grawe, 2003).

The stage of change measure, the URICA, was not related to working alliance development and did not appear to be a salient predictor of adolescent readiness to change as had been predicted by the researcher. Additionally, parent ratings of their adolescents' stage of change were not related to the adolescents' self-ratings on the URICA. Some explanations for the nonsignificant findings for the URICA in this study could be related to the reliability estimates, which were low at .70. Also, the participants in this study did not demonstrate consistent responses related to their stage of change beliefs as did previous studies with adolescents (Cohen et al., 2005; Fitzpatrick \& Irranejad, 2008), with as many participants rating themselves in the Maintenance stage as the Precontemplative stage.

Another potential explanation may lie in the fact that unlike in some previous research, adolescents in this study were asked to describe the problem that they were currently having, producing a diverse number of responses. Past research has used samples of adolescents with similar problems such as drug abuse, being detained at a juvenile facility, or being psychiatrically hospitalized (Cohen et al., 2005; Greenstein et al., 1999). Although it is possible that the URICA could be useful in an outpatient setting with adolescents with diverse problems, clearly defining the problem seems important. In this study, the URICA was administered without a full explanation of the need to identify a specific problem behavior when completing the measure. This was a problem with the research design and may have led to confusion for both the participants and their 
parents, contributing to the wide variability in scores. The findings and implications for this study are discussed in more detail below as well as suggestions for future research. Efficacy of Brief Group Treatment for Adolescents

Although not a specific hypothesis, this study showed that problem severity ratings decreased significantly while overall functioning improved over the course of the five week IOP group. While it is unknown what specific variables contributed to these findings, this self-rated improvement has implications for research in that outcome measurements such as the Ohio Scales (Ogles et al., 2001) are important to assess the efficacy of group psychotherapy for adolescents. Meta-analyses of group psychotherapy with children and adolescents have demonstrated its effectiveness (Hoag \& Burlingame, 1997; Shechtman, 2001). Often receiving support from parents, teachers, outside agencies, and third-party payers requires measurable outcome data. In clinical practice, outcome data are needed to show improvement in adolescents' functioning that can be linked to the treatment. These findings from the Ohio Scales suggest participants felt the group was helpful to them in some meaningful way. Future research is needed to tease out what specific aspects of group therapy adolescents find beneficial so that these variables can be included in group interventions.

\section{Relationship between Working Alliance and Group Cohesion}

The current study found strong correlations between working alliance ratings and ratings of group cohesion during the second half of the IOP group when measured at the midway point and after the last session. These findings support previous research on group cohesion and working alliance as being separate but related constructs with 
significant overlap (Johnson et al. 2005). Research on working alliance development with adolescents has shown similar results in that adolescents rate the working alliance higher when they feel the therapist is working with them to set goals and not pushing them to talk (Karver et al., 2008).

This study found correlations between cohesion and alliance only during the second half of the group, suggesting these variables took several sessions to develop. Shechtman (2001) indicated children and adolescents in group tend to self-disclose more quickly than adults and have different developmental needs including social skill learning and a desire to make friends. However, the IOP group for this study was not a closed group and accepted members in an open format, allowing for new group members to begin at any point. Thus, the adolescents in this study may have been inclined to develop relationships with fellow group members due to having a higher frequency of interactions, with fifteen sessions over five weeks. This aspect of the IOP group may demonstrate the impact of short-term treatment with adolescents. Meeting more frequently over a shorter time period may produce better outcomes than traditional weekly therapy. The finding that adolescents can perceive improvement in a short time period is hopeful and suggests that group treatment is a viable treatment option for adolescents. Overall, group leaders must understand the developmental level of adolescents and work to foster both the member to leader relationship as well as the member to member relationships to maximize positive outcomes. 


\section{Developing Working Alliance over Time}

Previous research on working alliance with adolescents has shown those who develop stronger alliances demonstrate greater treatment gains and have better outcome predictions than those who rate the alliance poorly (Hogue et al., 2006). With adolescents, certain therapist behaviors have been shown to affect alliance development negatively, such as criticism, overemphasizing information from previous sessions, and not pushing them to verbalize (Creed \& Kendall, 2005; Karver et al., 2008). For this study, participants did rate the alliance more positively over time but the ratings did not differ significantly from the beginning to end of the group. This may have been due to the small sample size. However, the current study demonstrated that adolescents were able to develop a positive working alliance in a relatively short time, by the first half of the IOP group. This finding supports the ability of group treatment to foster a positive atmosphere and to quickly develop the goals, task, and bond with members. Diamond et al. (1999) found alliance improvement was linked early on to specific alliance building techniques, such as the therapist presenting as an ally and willing to collaborate on goals. Since many group psychotherapy interventions are time-limited, future research could focus on designing interventions that foster and promote collaboration and other alliance building techniques. It is important for child and adolescent therapists to be educated on the most up to date literature with adolescents on alliance-building in both group and individual therapy. Taking these steps in research and training will foster alliance development and provide the greatest impact over time with this population. 
Stages of Change Beliefs over Time

The limited research on adolescents' stage of change beliefs in psychotherapy might suggest that participants would have entered the IOP group in the Precontemplative or Contemplation stages of change due to not being self-referred for therapy (Cohen et al., 2005; Derisley \& Reynolds, 2000; McConnaughy et al., 1982; Principe, 2005). However, this hypothesis was not supported in the current study. In fact, many participants' rated themselves in the Preparation or Maintenance stage of change. Contrary to previous research, less than half of the participants rated their initial stage of change as Precontemplation or Contemplation.

This study's limitations with regard to sample size and reliability for this measure suggest findings should be considered exploratory at best. However, perhaps it is presumptuous to suggest most adolescents begin therapy in Precontemplation or Contemplation as has been suggested in previous studies (Fitzpatrick \& Irranejad, 2008; Greenstein et al., 1999). Franko (1993) described adults in Preparation, Action or Maintenance stages as "Action Takers" and those in Precontemplation or Contemplation as "Contemplators." By virtue of being in treatment, adolescents may perceive they are Action Takers rather than Contemplators. Also, adolescents may not cognitively understand the meaning of the different stages of change. The five stages as they apply to adults may have different developmental considerations for adolescents, as reported by Hemphill and Howell (2000) who suggested adolescents may require some coaching to learn the skills and expectations necessary in each of the stages of change. These ideas 
should be explored in future research with adolescents to determine if measuring stages of change is appropriate for adolescents.

Adolescents who had undergone previous mental health treatment rated their stage of change as Contemplation most often in the current study while adolescents with no previous treatment rated themselves in Preparation or Maintenance most frequently. It is possible that adolescents with previous mental health treatment had low motivation to change their behavior during their previous encounters with mental health providers and continued to have low motivation to change when beginning the IOP group. The participants who rated themselves in Preparation or Maintenance may have felt that by virtue of their participation in a group psychotherapy intervention they were making changes in behavior. For clinical purposes, considering the adolescents' previous exposure to mental health services may provide some insight into their stage of change beliefs.

Working Alliance and Stages of Change

The current study predicted that adolescents would rate themselves in the Precontemplation or Contemplation stage of change and thus have more difficulty forming positive alliances with their therapist, or provide lower working alliance ratings than if they rated themselves in the Preparation, Action, or Maintenance stage of change. However, the current study found no relationship between the working alliance ratings and the stage of change measure. There are several possible explanations for these findings. Adolescents could have developed a positive working alliance with their therapist independent of their stage of change beliefs if they felt the therapists were 
working with them collaboratively. If adolescents did not feel as though they were the "identified patient" or forced to engage in treatment like many adolescents beginning therapy their alliance ratings might be higher (DiGuiseppe et al., 1996; Shirk \& Karver, 2008). A relationship between working alliance and stages of change may have been found if problems with the administration of the URICA had not occurred in this study.

More research with adolescents in a group intervention would be useful to tease out whether stage of change beliefs and working alliance are correlated. This study's findings related to working alliance and stage of change beliefs are interesting and worthwhile to consider in future research. Comparisons of these variables in both group treatment and individual treatment might determine the specific factors contributing to working alliance development and how stage of change beliefs impacts each type of treatment.

The current study also found no relationship between the parents' stage of change beliefs about their adolescents' problem behavior and the adolescents' stage of change beliefs prior to beginning the IOP group. Similarly, there was no relationship between the parents' stage of change beliefs about their adolescents' problem behavior and the adolescents' stage of change beliefs at the conclusion of the IOP group. This is not surprising given the variability in written responses from adolescent and adult pairs as to the "problem behavior" for the URICA. For example, one female participant cited "difficulties communicating with others" as her problem behavior while her parent cited "mental instability" as the problem for which the dyad was attending the IOP group. Not all participants' responses were this dramatically different; however, this variability was a 
major problem in the research design since the directions given were not specific enough, particularly to the adolescents. It is suggestive of underlying disagreement between parents and adolescents on the goals for group psychotherapy. This is an important implication for families in the same group in that discrepancies between parents and adolescents should be addressed prior to beginning therapy to mutually establish goals for treatment. In the next section, limitations for this study are discussed followed by recommendations for future research.

\section{Limitations of the Study}

This study contributed to the limited amount of existing research with adolescents on the constructs of working alliance and stages of change. It was the first known study to address these constructs with adolescents in group psychotherapy. However, there are several limitations and potentially confounding variables in this study's design. First, the sample size for this study was small. Initial $\mathrm{G}^{*}$ power analysis required 32 adolescents to obtain a medium effect size on all variables. Only 20 participants were obtained due to difficulties with the data collection process, problems recruiting participants, and attrition from both the IOP group and the study. Though post hoc $\mathrm{G}^{*}$ power analysis for the study's hypotheses found large effect sizes and effect sizes for some correlations were medium to large, generalizability is limited and more participants would have been helpful in teasing out the main effects of this study's variables. Generalizability is also limited given that the majority of participants in this study were Caucasian. This does not allow for analyses of possible cultural differences in working alliance and stage of change beliefs. These issues do not allow for generalizability to a 
larger population, only for implications and suggestions to be made for further research, practice and training.

This was a field study; data were collected in an outpatient clinic of a psychiatric hospital from one specific group. Field research can be challenging due to problems with recruitment of participants, and attrition. This study also collected data from an IOP group that only allowed six adolescents to join at a time for its 15 session cycle.

Unfortunately, during the year that data were collected the overall group census was uncharacteristically low. Additionally, there were five participants who dropped out of the study after only completing one IOP session and five others who had incomplete data. These factors, which are consistent with reported community levels of adolescent psychotherapy dropout and attrition rates (Warnick et al., 2011) contributed to the small sample size of this study. Establishing reasons for dropout and attrition were outside the scope of this study, but these findings could be interesting in future research and contribute to understanding the impact attrition has on mental health providers and treatment (Cornelius et al., 2001; Goodman et al., 1998). To address the issues with sample size, future research could include multiple groups at one clinic so as to increase potential participants, increasing the amount of incentive for participation in the study, and gathering data from larger groups, such as those that accept ten or more members at one time. These suggestions could improve overall participation and provide a larger sample size, which would reduce the potential of making a Type II error.

Another limitation of the current study relates to the IOP group leadership and structure. During the year of data collection, there was one male therapist and two 
female therapists facilitating the group, with two leaders facilitating each group session. The group members interacted closely with one another and with their therapists during group sessions. Each group member interacted fairly equally with the two group leaders over the course of the fifteen sessions and were asked to think about both therapists when completing the Working Alliance Inventory-Short Form Revised (WAI-SR) and the Group Climate Questionnaire-Short Form (GCQ-S). Having the group members think about more than one therapist while rating their working alliance was a potentially confounding variable. However, group psychotherapy is often led by more than one person and it was unrealistic to require participants to rate each therapist individually or to ask them to think about the therapist they liked "best." Overall, asking group members to rate their therapists as a unit may have been confusing for adolescents and may have contributed to the lack of significant findings for alliance and group cohesion ratings over time.

Another limitation of the current study is the use of self-report measures. These have been found to be problematic as they are based on individuals' opinions of themselves or their ratings of the group, therapist, or problem behavior. It was not part of the research design to require the therapists or an outside observer to complete the working alliance or group cohesion measures. This is a limitation of the study as there are not outside observer ratings to corroborate the findings on all assessment measures. Disadvantages of self-report data include participant bias, potential for answering in a way that may "please" the researcher or therapist, and inaccurate data (Chan, 2009). However, Chan (2009) described the advantages of self-report measures as they are easy 
to complete, they obtain the participants' view most directly, and are a means of gathering information about the person's opinion when observational data or outside observer ratings would not be sufficient.

In a comprehensive review of the literature, there were no studies found investigating the constructs of working alliance and stages of change in a group psychotherapy format with adolescents. The research design for this study was limited by the lack of related studies from which to build upon and identify important next steps for research. Kymissis (1998) found no strong consensus in the research on when the development of working alliance occurs in a group setting with adolescents and how it impacts other group processes, such as cohesion. Thus, the current study attempted to simulate the trajectory of working alliance development in individual therapy by gathering data at four specific points during the group intervention. The URICA was utilized to assess stage of change beliefs but because in this study the participant was asked to identify a "problem behavior" the measure became a confounding variable. This was a limitation for this study in that even if the adolescents were able to identify a problem behavior, the IOP group may not have directly worked on it during sessions in the same way that it might have been addressed in individual therapy. Overall, using the URICA in a group format may have been a limitation for this study.

Finally, the heterogeneity of the participants' mental health treatment histories and expectations for therapy may have been a confounding variable in this study. The specific reasons for the participants in this study to have sought mental health treatment are unknown. Future research could include more questions related to previous treatment 
and type of therapy provided on the demographic questionnaire. Comparing participants who had received previous therapy to those that had not may have contributed to the lack of significant findings in stage of change beliefs. Future research may explore previous mental health treatment history and how it impacts adolescents' stage of change beliefs and working alliance development. It is possible that either a positive or negative earlier therapy experience may affect their response to entering a new treatment. It is also important to examine what adolescents knew about group treatment prior to beginning this type of treatment as pretreatment expectations have been shown to be important in predicting both working alliance development and outcome with adults (Patterson et al., 2008). Pretreatment expectations might have been a reason for the lack of significant findings within this group. This and other recommendations for future research are outlined below.

\section{Recommendations for Future Research}

This study gathered data from adolescents to assess the relationships between working alliance, stages of change, and group cohesion. The IOP group met the researcher's requirements for a time-limited multi-family group in order to investigate both process and outcome. However, the difficulties with data collection and limited significant findings from this study highlight the need for future research. Adolescents have different needs than adults in psychotherapy, requiring research to develop the most efficacious treatment interventions to engage this population. Adolescents are participating in therapy with greater frequency, there are limited mental health resources available, and the research suggests that groups are effective. These provide a 
compelling reason to conduct group therapy with adolescents (Kataoka et al., 2002).

Clients increasingly require third-party payer sources to gain access to psychotherapy, and groups are covered by some insurance plans and state-funded programs due to their proven efficacy and time-limited nature. Group therapy has been shown to be effective for adolescents in multiple settings (Hoag \& Burlingame, 1997; Shechtman, 2001). While the effectiveness of group psychotherapy is clear, future research should be conducted with adolescent groups to flesh out the specific variables contributing to positive outcomes.

Studies with a larger sample size would allow for more generalizable findings and may possibly demonstrate a more stable relationship between the constructs of working alliance, stages of change, and group cohesion. A sample size with more cultural diversity may allow for better understanding of how these constructs impacts various cultures. A larger sample size may have been able to determine specific relationship variables that may have impacted working alliance development, cohesion, and stage of change beliefs. However, one of this study's strengths is that it was conducted in the field with adolescents in a manualized treatment format. Future research should be conducted with these types of groups to determine what variables contribute to the success of manualized treatment with adolescents.

Adjusting the data collection process may provide interesting and significant findings in future research. For instance, measuring the working alliance and group cohesion after each session of the group would have allowed for additional data and might have demonstrated a more accurate trajectory of these variables in the current 
study. Sitting down with adolescents and their parent/caregiver prior to the study and explaining the stages of change model and how to apply it to the URICA may have made a difference in ratings of their stage of change beliefs. Involving the group leader in this discussion may have impacted working alliance ratings and group cohesion as well. It may have been helpful to measure participants overall functioning and problem severity ratings using the Ohio Scales three or six months after the intervention to determine if gains made were kept.

One of the most important findings in the current study was that problem severity ratings decreased over the course of the group while overall functioning improved. Given this was a short term group that lasted 5 weeks with 15 sessions in all, it is promising to consider that even brief treatments with adolescents have the potential to affect changes. Future research could focus on how to make brief treatments even more impactful for this population. Improvement in this area may be related to group selection processes, such as screening processes for potential members, assessing past mental health treatment, and assessing barriers to treatment such as prior dropout from individual or group therapy, levels of parental stress, socio-economic status, and severity of adolescent symptoms (Spirito et al., 2011; Warnick et al, 2011). Requiring a pre-group meeting with potential participants to discuss these issues as well as explain and assess stage of change beliefs may improve the power of brief group psychotherapy and decrease attrition. 


\section{Conclusions}

This study set out to measure the relationship between working alliance development and stages of change in an adolescent psychotherapy group. There is limited research with adolescents in psychotherapy, particularly on the constructs of working alliance and stages of change. It was the first known study to examine these constructs in a group format, with important implications for adolescents in psychotherapy. Overall, adolescents improved in general functioning and decreased symptom severity during the course of the group. This study also found group cohesion and working alliance to be correlated over the course of the group, with higher correlations after the second half of the group. This supports research on the development of group cohesion and suggests that the concepts of working alliance and group cohesion may be related for adolescents. More research is needed to understand the extent of this relationship and if it is important to assess working alliance and group cohesion individually. Implications for therapists include focusing on specific aspects of group development related to cohesion as well as working on the development of the working alliance during beginning group sessions. Fostering therapist and member relationships may be as important as fostering member to member relationships with adolescent populations in groups.

The current study did not support previous research on stage of change beliefs with adolescents. This could be due to several factors. A small sample size, previous mental health treatment, and the use of the measure in a group versus individual therapy contributed to the nonsignificant findings for stages of change. The low internal 
consistency of the URICA in this study is perhaps one of the factors in understanding why the results were nonsignificant as well as the problems encountered with administration. It may be unwise to assume adolescents begin therapy in the Precontemplation or Contemplation stage of change as has been proposed in previous literature (Fitzpatrick \& Irannejad, 2008; Greenstein et al., 1999). Other factors might include the adolescents' perception of the problem behavior and the amount of agreement between the parent and adolescent on the problem. These issues may play a role in how the adolescent rates their stage of change beliefs.

Cognitive and developmental level also impact understanding of stage of change beliefs for adolescents (Cohen et al., 2005). Adolescents may not be motivated to change behaviors despite previous participation in mental health treatment just as participants beginning treatment may be motivated to change behaviors quickly. For group psychotherapy research, participation in a group may be viewed by some adolescents as more "low-risk" than individual therapy in that they would feel less put on the spot or feel pressure to interact one-on-one with an individual therapist. However, it is important for clinicians to consider that there may be a therapeutic response in simply presenting to mental health treatment for adolescents and that this can impact their thinking about behavior change.

It is important to continue studying adolescents to determine how process and outcome variables affect change in psychotherapy. Therapists are required to wear many hats when conducting group psychotherapy, focusing on group development, member to member relationships, and member to group leader relationship while effectively 
delivering the content material to the group. This study contributes to the existing research on working alliance development with adolescents and group cohesion development in adolescent group. This study's findings suggest more research is needed to fully understand the impact of stage of change beliefs on psychotherapy with this population. There are multiple factors contributing to group processes and outcomes, including clients' previous exposure to mental health treatment, format and type of psychotherapy and relationship variables such as working alliance and group cohesion. 


\section{References}

Bakali, J.V., Baldwin, S.A., \& Lorentzen, S. (2009). Modeling group process constructs at three stages in group psychotherapy. Psychotherapy Research, 19, 332-343.

Bickman, L., Rosef-Williams, J., Salzer, M. S., Summerfelt, W. T., Noser, K., Wilson, S. J., \& Karver, M. S. (2000). What information do clinicians value for monitoring adolescent client progress and outcomes? Professional Psychology, 31(1), 70-74.

Bordin, E. S. (1979). The generalizability of the psychoanalytic concept of the working alliance. Psychotherapy: Theory, Research, and Practice, 16(3), 252-260.

Bordin, E. S. (1994). Theory and research on the therapeutic working alliance: New directions. In A. O. Horvath \& L. S. Greenberg (Eds.), The working alliance: Theory, research, and practice. (p. 13-37). New York: John Wiley \& Sons.

Brogan, M. M., Prochaska, J. O., \& Prochaska, J. M. (1999). Predicting termination and continuation status in psychotherapy using the transtheoretical model. Psychotherapy, 36(2), 105-113.

Budman, S.H., Soldz, S., Demby, A., Feldstein, M., Springer, T., Davis, M.S. (1989). Cohesion, alliance, and outcome in group psychotherapy. Psychiatry, 52, 339-350.

Burlingame, G.M., Fuhriman, A., \& Johnson, J.E. (2001). Cohesion in group psychotherapy. Psychotherapy, 38, 373-379.

Cicchetti, D.V. (1994). Guidelines, criteria, and rules of thumb for evaluating normed and standardized assessment instruments in psychology. Psychological Assessment, 6, 284-290.

Chan, D. (2009). So why ask me? Are self report data really that bad? In C.E. Lance \& R.J. Vandenberg (Eds.). Statistical and methodological myths and urban legends: Doctrine, verity, and fable in the organizational and social sciences (pp 309-335). New York: Routledge.

Church, E. (1994). The role of autonomy in adolescent therapy. Psychotherapy, 31(1), 101-108. 
Cohen, J. (1988). Statistical power analysis for the behavioral sciences. Hillsdale, NJ: Erlbaum.

Cohen, P. J., Glaser, B. A., Calhoun, G. B., Bradshaw, C. P., \& Petrocelli, J. V. (2005). Examining readiness for change: A preliminary evaluation of the University of Rhode Island Change Assessment with incarcerated adolescents. Measurement and Evaluation in Counseling And Development, 38, 45-62.

Corey, M.S., \& Corey, G. (2006). Groups: Process and Practice. New York, New York: Thompson, Brooks, Cole.

Cornelius, J.R., Pringle, J., Jernigan, J., Kirisci, L., Clark, D.B. (2001). Correlates of mental health utilization and unmet need among a sample of male adolescents. Addictive Behaviors, 26, 11-19.

Creed, T.A. \& Kendall, P.C. (2005). Therapeutic alliance-building behavior within a cognitive-behavioral treatment for anxiety in youth. Journal of Consulting and Clinical Psychology, 73, 498-505.

Crowe, T.P., \& Grenyer, B.F. (2008). Is the therapist alliance or whole group cohesion more influential in group psychotherapy outcomes? Clinical Psychology and Psychotherapy, 15, 239-246.

Derisley, J., \& Reynolds, S. (2000). British Journal of Clinical Psychology, 39, $371-382$

Derisley, J.,\& Reynolds, S. (2002). Evaluation of the stages of change scales to measure client readiness for treatment in a mental health sample. Behavioural and Cognitive Psychotherapy, 30, 217-222.

Diamond, G. M., Liddle, H. A., Hogue, A., \& Dakof, G. A. (1999). Alliance building interventions with adolescents in family therapy: A process study. Psychotherapy: Theory, Research, Practice, and Training, 36(4), 355-368.

DiGiuseppe, R., Linscott, J., \& Jilton, R. (1996). Developing the therapeutic alliance in child-adolescent psychotherapy. Applied and Preventive Psychology, 5, 85-100.

Dolan, R. T., Arnkoff, D. B., \& Glass, C. R. (1993). Client attachment style and the psychotherapist's interpersonal stance. Psychotherapy, 30(3), 408-412. 
Eaton, T. T., Abeles, N., \& Gutfreund, M. J. (1988). Therapeutic alliance and outcome: Impact of treatment length and pretreatment symptomology. Psychotherapy, 25(4), 536-542.

Eltz, M., Shirk, S., \& Sarlin, N. (1995). Alliance formation and treatment outcome among maltreated adolescents. Child Abuse and Neglect, 19(4), 419-431.

Emmerling, M.E., \& Whelton, W.J. (2008). Stages of change and the working alliance in psychotherapy. Psychotherapy Research, 19(6), 687-698.

Faw, L. , Hogue, A., Johnson, S., Diamond, G.M., Liddle, H.A. (2005). The Adolescent Therapeutic Alliance Scale (ATAS); Initial psychometrics and prediction of outcome in family-based substance abuse prevention counseling. Psychotherapy Research, 15(1-2), 141-154.

Fitzpatrick, M. R., \& Irannejad, S. (2008). Adolescent readiness for change and the working alliance in counseling. Journal of Counseling and Development, 86, 438445.

Florsheim, P., Shotorbani, S., Guest-Warnick, G., Barratt, T., \& Hwang, W. (2000). Role of the working alliance in the treatment of delinquent boys in community-based programs. Journal of Clinical Child Psychology, 29, 94-107.

Franko, D.L. (1998). Ready or not? Stages of change as predictors of brief group therapy outcome in bulimia nervosa. Group, 21, 39-45.

Freud, S. (1912). The dynamics of transference. In J. Starchey (Ed.), The standard edition of the complete psychological works of Sigmund Freud (pp. 99-108).

London, England: Hogarth Press.

Garcia, J. A., \& Weisz, J. R. (2002). When youth mental health care stops: Therapeutic relationship problems and other reasons for ending youth outpatient treatment. Journal of Consulting and Clinical Psychology, 70(2), 439-443.

Greenberg, L. S., \& Pinsof, W. M. (1986). The psychotherapeutic process: A research handbook. New York: Guilford Press.

Greenson, R. R. (1965). The working alliance and the transference neurosis. The Psychoanalytic Quarterly, 34, 155-181. 
Greenstein, D. K., Franklin, M. E., \& McGuffin, P. (1999). Measuring motivation to change: An examination of the University of Rhode Island Change Assessment Questionnaire (URICA) in an adolescent sample. Psychotherapy, 36(1), 47-55.

Goodman, S.H. et al. (1998). Measurement of risk for mental disorders and competence in a psychiatric epidemiologic community survey: The National Institute of Mental Health methods for the epidemiology of child and adolescent mental disorders (MECA) study. Social Psychiatry and Psychiatric Epidemiology, 33, 162-173.

Gusella, J., Butler, G., Nichols, L., \& Bird, D. (2002). A brief questionnaire to assess readiness to change in adolescents with eating disorders: Its applications to group therapy. European Eating Disorders Review, 11, 58-71.

Hanson, W. E., Curry, K. T., \& Bandalos, D. L. (2002). Reliability generalization of Working Alliance Inventory scale scores. Educational and Psychological Measurement, 62, 659-673.

Hartley, D. E., \& Strupp, H. H. (1983). The therapeutic alliance: Its relationship to outcome in brief psychotherapy. In J. Masling (Ed.), Empirical studies of psychoanalytic theories (pp. 1-38). Hillsdale, NJ: Erlbaum.

Hartley, D. E., \& Strupp, H. H. (1994). The therapeutic alliance as interpersonal process. In A. O. Horvath \& L. S. Greenberg (Eds.), The working alliance: Theory, research, and practice. (pp. 51-84). New York: John Wiley \& Sons, Inc.

Hatcher, R. L., \& Gillaspy, J. A. (2006). Development and validation of a revised short version of the working alliance inventory (WAI-SR). Psychotherapy Research 16(1), $12-25$.

Hawley, K., \& Weisz, J. (2005). Youth versus parent working alliance in usual clinical care: distinctive associations with retention, satisfaction, and treatment outcome. Journal of Clinical Child And Adolescent Psychology, 34(1), 117-128.

Hemphill, J. F., \& Howell, A. J. (2000). Adolescent offenders and stages of change. Psychological Assessment, 12(4), 371-381.

Henry, W. P., \& Strupp, H. H. (1994). The therapeutic alliance as an interpersonal process. In A.O. Horvath \& L.S. Greenburg (Eds.). The working alliance: Theory, research, and practice (pp. 51-84). New York: Wiley. 
Herzog, T. A. (2007). Are the stages of change for smokers qualitatively distinct? An analysis using an adolescent sample. Psychology of Addictive Behaviors, 21(1),120125.

Hill, C. E. (2005). Therapist techniques, client involvement, and the therapeutic relationship: Inextricably intertwined in the therapy process. Psychotherapy, 42(4), 431-442.

Hoag, M.J. \& Burlingame, G.M. (1997). Evaluating the effectiveness of child and adolescent group treatment: A meta-analytic review. Journal of Clinical Child Psychology, 26, 234-246.

Horvath, A. (2001). The alliance. Psychotherapy: Theory, Research, Practice, and Training, 38(4),365-372.

Horvath, A., \& Bedi, R. P. (2002). The alliance. In Norcross, J.C. (Ed.) Psychotherapy relationships that work. Oxford: Oxford University Press.

Horvath, A., \& Greenberg, L. (1986). The development of the Working Alliance Inventory. In L. S. Greenberg \& W. M. Pinsof (Eds), The psychotherapeutic process: A research handbook. (pp. 529-556). New York: Guilford.

Horvath A., \& Luborsky, L. (1993). The role of the therapeutic alliance in psychotherapy. Journal of Consulting and Clinical Psychology, 61(4), 561-573.

Horvath, A, \& Symonds, B. D., (1991). Relation between working alliance and outcome in psychotherapy: A meta-analysis. Journal of Counseling Psychology, 38(2),139149.

Johnson, J.E., Burlingame, G.M., Olsen, J.A., Davies, D.R., \& Gleave, R.L. (2005). Group climate, cohesion, alliance, and empathy in group psychotherapy: Multilevel structural equation models. Journal of Counseling Psychology, 52, 310-321.

Johnson, S., Hogue, A., Diamond, G., Leckrone, J., \& Liddle, H. A. (1998) Scoring Manual for the Adolescent Therapeutic Alliance Scale (ATAS). Unpublished manuscript, Temple University, Philidelphia. 
Joyce, A. S., \& Piper, W. E. (1998). Expectancy, the therapeutic alliance, and treatment outcome in short-term individual psychotherapy. Journal of Psychotherapy Practice and Research, 7, p. 236-248.

Joyce, A.S., Piper, W.E., \& Ogrodniczuk, J.S. (2007). Therapeutic alliance and cohesion variables as predictors of outcome in short-term group psychotherapy. International Journal of Group Psychotherapy, 57(3), 269-296.

Karver, M., Handelsman, J., Fields, S., \& Bickman, L. (2006). Meta-analysis of therapeutic relationship variables in youth and family therapy: The evidence for different relationship variables in the child and adolescent treatment outcome literature. Clinical Psychology Review, 26, 50-65.

Karver, M., Shirk, S., Handelsman, J., Fields, S., Crisp, H., Gudmundsen, G., McMakin, D. (2008). Relationship processes in youth psychotherapy: Measuring alliance, alliance-building behaviors, and client involvement. Journal of Emotional and Behavioral Disorders, 16(1), 15-28.

Kataoka, S. H., Zhang, L., \& Wells, K. B. (2002). Unmet need for mental health care among

U.S. Children: Variation by ethnicity and insurance status. American Journal of Psychiatry, 159(9), 1548-1555.

Kazdin, A. E. (1990). Premature termination from treatment among children referred for antisocial behavior. Journal of Child Psychology and Psychiatry and Allied Disciplines, 31(3), 415-425.

Kazdin, A. E. (1996). Dropping out of child psychotherapy: Issues for research and implications for practice. Clinical Child Psychology and Psychiatry, 1(1), 133-156.

Kazdin, A. E., Holland, L., \& Crowley, M. (1997). Family experience of barriers to treatment and premature termination from child therapy. Journal of Consulting and Clinical Psychology, 65, 453-463.

Kazdin, A. E., Marciano, P. L., \& Whitley, M. K. (2006). Child-therapist and parenttherapist alliance and therapeutic change in the treatment of children referred for oppositional, aggressive, and antisocial behavior. Journal of Child Psychology and Psychiatry, 73(4), 436-445. 
Kazdin, A., Seigel, T, and Bass, D. (1990). Drawing on clinical practice to inform research on child and adolescent psychotherapy: Survey of practitioners. Professional Psychology: Research and Practice, 21(3), 189-198.

Kymissis,P., (1996). Developmental approach to group development and socialization. In P. Kymissis \& J. Halperin (Eds.). Group therapy with children and adolescents. (pp. 21-35). Washington, D.C.: American Psychiatric Press, Inc.

Lambert, M. J. (2005). Psychotherapy outcome research: Implications for integrative and eclectical therapists. In J.C. Norcross \&M.R. Godfried (Eds.), Handbook of psychotherapy integration (pp. 94-129). New York: Basic Books.

Leichtentritt, J., \& Schectman, Z. (1998). Therapist, trainees, and child verbal response modes in child group therapy. Group Dynamics, 2, 36-47.

Levesque, D. A., Gelles, R. J., \& Velicer, W. F. (2000). Development and validation of a stages of change measure for men in batterer treatment. Cognitive Therapy and Research, 24(2), 175-199.

Luborsky, L. Crits-Christoph, P., Mintz, J. \& Auerbach, A. (1988). Who Will Benefit from Psychotherapy? New York: Basic Books.

Luborsky, L., Crits-Cristoph, P., Alexander, L., Margolis, M., \& Cohen, M. (1983).

Two helping alliance methods for predicting outcomes in psychotherapy: A counting signs vs. a global rating method. Journal of Nervous and Mental Disease, 171, 480491.

Luborsky, L., Singer, B., \& Luborsky, L. (1975). Comparative studies of psychotherapies: Is it true that everybody has won and all must have prizes"? Archives of General Psychiatry, 32, 995-1008.

MacKenzie, K.R. (1983). The clinical application of a group climate measure. In R.R. Dies \& K.R. MacKenzie (Eds.), Advances in Group Psychotherapy: Integrating Research and Practice. (pp. 159- 170). New York: International Universities Press.

Marmar, C., Weiss, D. S., \& Gaston, L. (1989). Toward the validation of the California Therapeutic Alliance Rating System. Psychological Assessment: A Journal of Consulting and Clinical Psychology, 1, 46-52. 
Martin, D. J., Garske, J. P., \& Davis, M. K. (2000). Relation of the therapeutic alliance with outcome and other variables: A meta-analytic review. Journal of Consulting and Clinical Psychology, 68(3),438-450.

Marziali, E., Monroe-Blum, H., McCleary, L. (1997). The contribution of group cohesion and group alliance to the outcome of group psychotherapy. International Journal of Group Psychotherapy, 47, 475-497.

McConnaughy, E. I., DiClemente, C. C., Prochaska, J. O., and Velicer, W. F. (1989). Stages of change in psychotherapy: A follow-up report. Psychotherapy, 26, 494-503.

McConnaughy, E. I., Prochaska, J. P., \& Velicer, W. F. (1983). Stages of change in psychotherapy: Measurement and sample profiles. Psychotherapy, 20, 368-375.

Miller, W. R., \& Tonigan, J. S. (1996). Assessing drinkers motivation for change: The Stages of Change Readiness and Treatment Eagerness Scale (SOCRATES). Psychology of Addictive Behaviors, 10, 81-89.

Morrisey-Kane, E., \& Prinz, R. J. (1999). Engagement in child and adolescent treatment: The role of parental cognitions and attributions. Clinical Child and Family Psychology Review, 2, 183-198.

Munder, T., Wilmers, F., Leonhart, R., Linster, H.W., \& Barth, J. (2010). Working Alliance Inventory-Short Revised (WAI-SR): Psychometric properties in outpatients and inpatients. Clinical Psychology and Psychotherapy, 17, 231-239.

Napper, L. E., Fisher, D. G., Reynolds, G. L., Wood, M. M., Jaffe, A., \& Klahn, J. A. (2008). Convergent and discriminant validity of three measures of stage of change. Psychology of Addictive Behaviors, 22(3), 362-371.

Oetzel, K. B., \& Scherer, D. G. (2003). Therapeutic engagement with adolescents in psychotherapy. Psychotherapy: Theory, Research, Practice, and Training, 40(3), 215-225.

Ogles, B.M, Melendez, G., Davis, D.C., \& Lunnen, K.M. (2001). The Ohio Scales: Practical outcome assessment. Journal of Child and Family Studies, 10, 199-212.

Olfson, M., Gameroff, M. J., Marcus, S. C., et al. (2003). Outpatient treatment of child and adolescent depression Archives of General Psychiatry, 60, 1236-1242. 
Patterson, C. L., Uhlin, B., \& Anderson, T. (2008). Clients' pretreatment counseling expectations as predictors of the working alliance. Journal of Counseling Psychology, 55(4), 528-534.

Pinsof, W. M. (1994). An integrative systems perspective on the therapeutic alliance: Theoretical, clinical, and research implications. In A. O. Horvath \& L. S. Greenberg, (Eds.), The working alliance: theory, research, and practice. (pp. 173-198). New York: John Wiley \& Sons, Inc.

Piper, W.E., Marrache, M., Lacroix, R., Richardsen, A.M., Jones, B.D. (1983). cohesion as a basic bond in groups. Human Relations, 36, 93-108.

Principe, J. M., Marci, C. D., Glick, D. M., \& Albon, J. S. (2006). The relationship among patient contemplation, early alliance, and continuation in psychotherapy. Psychotherapy: Research, Practice, Training, 43(2), 238-243.

Prochaska, J. O., \& DiClemente, C. C. (1982). Transtheoretical therapy: Toward a more integrative model of change. Psychotherapy: Theory, Research, and Practice, 19, 276-288.

Prochaska, J. O., \& DiClemente, C. C. (1992). The transtheoretical approach. In J.C. Norcross \& M. R. Goldfried (Eds). Handbook of psychotherapy integration, (pp. 300334). New York: Basic Books.

Prochaska, J. O., \& Norcross, J. C. (2002). Stages of change. In J. C. Norcross (Ed.), Psychotherapy relationships that work. Oxford: Oxford University Press.

Prochaska, J. O., DiClemente, C. C., \& Norcross, J. C. (2003). In search of how people change: Applications to addictive behaviors. In P. Salovey \& A. J. Rothman, (Eds.) Social Psychology And Health. New York: Psychology Press.

Prochaska, J. O., Norcross, J. C., \& DiClemente, C. C. (1992). In search of how people change: Applications to addictive behaviors. American Psychologist, 47, 102-113.

Prochaska, J. O., Norcross, J. C., \& DiClemente, C. C. (1994). Changing for good. New York: William Morrow and Co.

Prochaska, J.O., \& Prochaska, J.M. (2004). Assessment as intervention within the Transtheoretical Model. In M.E. Maruish, (Ed). The use of psychological testing and 
for treatment planning and outcome assessment, Volume 3. New Jersey: Lawrence Erlbaum Associates, Inc.

Prochaska, J. O., Redding, C. A., Harlow, L. L., Rossi, J. S., \& Velicer, W. F. (1994). The transtheoretical model of change and HIV prevention: A review. Health Education, 21, 471-486.

Robbins, M. S., Mayorga, C. C., Mitrani, V. B., Szapocznik, J., Turner, C. W., \& Alexander, J. F. (2008). Adolescent and parent alliances with therapists in brief strategic family therapy with drug-using Hispanic adolescents. Journal of Marital and Family Therapy, 34(3), 316-328.

Rollnick, S., Heather, N., Gold, R., \& Hall, W. (1992). Developmemt of a short "readiness to change "questionnaire for use in brief, opportunistic intervention among excessive drinkers. British Journal of Addiction, 87, 743-754.

Shechtman, Z. (2001). Child group psychotherapy in the school at the threshold of a new millennium. Journal of Counseling and Development, 80, 293-300.

Sherwood, V. (1990). The first stage of treatment with the conduct disordered adolescent: Overcoming narcissistic resistance. Psychotherapy,27(3), 380-387.

Shirk, S. R., \& Karver, M. (2003). Prediction of treatment outcome from relationship variables in child and adolescent therapy: A meta-analytic review. Journal of Consulting and Clinical Psychology, 71(3), 452-464.

Shirk, S. R., \& Saiz, C. (1992). Clinical, empirical, and developmental perspectives on the relationship in child psychotherapy. Development and Psychopathology,4, 713728 .

Shirk, S. R., Gudmundson, G. R., Crisp-Kaplinski, H., \& McMakin, D. L. (2008). Alliance and outcome in cognitive-behavioral therapy for adolescent depression. Journal of Clinical Child \& Adolescent Psychology, 37(3), 631-639.

Shirk, S. R., Gudmundson, G. R., McMakin, D., Dent, H. C., \& Karver, M. (2003). Raters manual for The Alliance Building Behaviors Scale. Unpublished manual, University of Denver, Denver, CO. 
Smith, M. L., \& Glass, G. V. (1977). Meta-analysis of psychotherapy outcome studies. American Psychologist, 41, 752-760.

Spirito, A. et al. (2011). Outpatient psychotherapy practice with adolescents following psychiatric hospitalization for suicide ideation or a suicide attempt. Clinical Child Psychology Psychiatry, 16, 53-64.

Surgeon General. (2008). Mental health: A report of the Surgeon General. Retrieved on 4/29/09 from: http://www.surgeongeneral.gov/library/mentalhealth/chapter1/sec4.html\#chap3.

Sutton, S. (1996). Can "states of change" provide guidance in the treatment of addictions? A critical example of Prochaska and DiClemente's model. In G. Edwards \& C. Dare (Eds.) Psychotherapy, psychological treatments, and the addictions. Cambridge: Cambridge University Press.

Sutton, S. (2001). Back to the drawing board? A review of applications of the trantheoretical model to substance use. Addiction, 96, 175-186.

Tabachnick, B. G., \& Fidell, L. S. (2007). Using multivariate statistics. Boston: Pearson Education Inc.

Tracey, T. J., \& Kokotovic, A. M. (1989). Factor structure of the Working Alliance Inventory. Psychological Assessment: A Journal of Consulting and Clinical Psychology, 1, 207-210.

Van Andel, P., Erdman, R.A., Karsdorp, P.A., Appels, A., Trijsburg, R.W. (2003). Group cohesion and working alliance: Prediction of treatment outcome in cardiac patients receiving cognitive behavioral group psychotherapy. Psychotherapy and Psychosomatics, 72, 141-149.

Velasquez, M.M., Maurer, G.G., Crouch, C., \& DiClemente, C.C. (2001). Group Treatment for Substance Abuse: A Stage of Change Therapy Manual. New York: Guilford Press.

Velicer, W. F., Fava, J. L., Prochaska, J. O., Abrams, D. B., Emmons, K. M., \& Pierce, J. (1995). Distribution of smokers by stage in three representative samples. Preventive Medicine, 24, 401-411. 
Velicer, W. F., Prochaska, J. O., Fava, J. L., Norman, G. J, \& Redding, C. A. (1998). Smoking cessation and stress management; Applications of the Transtheoretical Model of behavior change. Homeostasis, 38, 216-233.

Velicer, W. F., Prochaska, J. O., Rossi, J., \& DiClemente, C. C. (1996) A criterion measurement model for addictive behaviors. Addictive Behaviors, 21, 555-584.

Warnick, E.M., Gonzalez, A., Weersing, R., Scahill, L., \& Woolston, J. (2011). defining dropout from youth psychotherapy: How definitions shape the prevalence and predictors of attrition. Child and Adolescent Mental Health, 75, 25-35.

Wampold, B. E. (2001). The great psychotherapy debate: Models, methods, and findings. Mahweh, New Jersey: Lawrence Erlbaum Associates.

Weisz, J. R., Weiss, B., Alicke, M. D., \& Klotz, M. L. (1987). Effectiveness of psychotherapy with children and adolescents: Meta-analytic findings for clinicians. Journal of Consulting and Clinical Psychology, 55(4), 542-549.

Yalom, I., \& Leszcz, M. (2005). The theory and practice of group psychotherapy $\left(5^{\text {th }}\right.$ edition). New York: Basic Books.

Zack, S. E., Castonguay, L. G., Boswell, J. F. (2007). Youth working alliance: A core clinical construct in need of empirical maturity. Harvard Review Psychiatry, 15(6), 278-288. 
APPENDIX A

INVITATION FLYER 


\title{
Study Title: The Relationship Between Adolescents' Stage of Change and Their Ability to Establish a Working Alliance in Psychotherapy
}

\author{
Dear Potential Participant:
}

I am a doctoral candidate in Counseling Psychology at the University of Denver under the supervision of Dr. Maria Riva. I am conducting my dissertation on adolescents' level of motivation to change a particular behavior and how this may affect their ability to develop a working alliance with their therapist. This research will provide important information about psychotherapy with adolescents. Your participation will be greatly appreciated.

You and your adolescent are invited to participate in this study if your adolescent meets the following criteria:

1. You have an adolescent between the ages of 12 and 17 years old.

2. Your adolescent will be participating in IOP (intensive outpatient) treatment at the Children's Hospital.

3. Your adolescent is not actively suicidal, homicidal, or experiencing psychotic symptoms.

4. Your adolescent has not been hospitalized for psychiatric reasons in the last 14 days.

5. You will be present for the initial IOP treatment session and at week five of IOP treatment in order to complete two short questionnaires regarding your adolescent's participation in therapy.

You as the parent or caregiver will be asked to complete two short questionnaires, a demographic questionnaire and a questionnaire designed to measure your beliefs about your adolescent's level of motivation for therapy. These will be completed prior to your adolescent's participation in IOP treatment. After your adolescent has participated in five weeks of IOP treatment, you will be asked to complete another assessment to measure your adolescent's level of motivation for therapy. Each of the assessments should take approximately 10 minutes to complete. Your adolescent will complete several brief questionnaires throughout the course of the IOP program before or after the weekly sessions. After completion of the IOP group, your adolescent will be provided with a Target gift card in the amount of $\$ 15$.

If you would like to know more about this study or are willing to participate in the study, please fill in your name and telephone number. By providing your name and contact information, you are consenting to be contacted to learn more about the study. You are not consenting to participate in the study. If you would prefer to speak to me directly, my telephone number and email are listed below. Thank you for your time and consideration.

Sincerely,

Phone (720) 335-8244

Jennifer Grote

Email: jgrote2@du.edu

Caregiver Name

Phone Number 
APPENDIX B

INFORMED CONSENTS 


\section{INFORMED CONSENT (PARENT)}

You and your adolescent are invited to participate in a study about working with adolescent clients in an individual therapy setting. This study is being conducted by Jennifer Grote, M.Ed. under the supervision of Dr. Maria Riva as part of the requirements for the doctoral degree in Counseling Psychology at the University of Denver. This study is being conducted to better understand adolescent clients' level of motivation and readiness to change at the outset of individual therapy. This study will look at the relationship between the adolescent clients' motivation to change and their ability to develop a working alliance with their therapist. The working alliance simply means the bond between the client and therapist.

During the course of the study, you as the parent or caregiver will be asked to complete two short questionnaires prior to the first session of group psychotherapy. The first questionnaire consists of demographic information. The second questionnaire is the University of Rhode Island Change Assessment (URICA), which is a 32-item assessment measure to determine a person's current level of motivation to change a problem behavior. Following the last group psychotherapy session you will be asked to complete the URICA questionnaire to assess the current level of motivation to change a problem behavior. Each questionnaire will take approximately 10 minutes to complete.

Your adolescent will be asked to complete a demographic questionnaire as well as the URICA questionnaire prior to the first session of group psychotherapy. Following the first, fourth, seventh and fifteenth session of group psychotherapy, your adolescent will be asked to complete the WAI-SR questionnaire to assess the development of the working relationship. After session fifteen, your adolescent will also be asked to complete the URICA assessment.

There are minimal foreseeable risks or discomforts involved in your and your adolescent's participation in this study. You or your adolescent might experience some psychological discomfort in thinking about an emotionally sensitive problem. Although it is not anticipated that the questionnaires will cause you or your adolescent any undo stress, if this does occur, you and your adolescent can choose not to complete the questionnaires and terminate participation at any time. There will be no penalty to you or your adolescent if you decide to withdraw from the study.

This study's findings may be presented and published for professional use; however, no identifying information about you or your adolescent will be used in any written or verbal form. Your consent forms and any other identifying materials will be kept separate from your completed questionnaires in order to maintain confidentiality. Additionally, your 
individual therapist will not be provided with information about your completed questionnaires. A code number will be assigned and used instead of your name, and all data will be kept in secured, locked files.

If you have any questions or concerns about this study, please contact Jennifer Grote at (720) 335-8244 or Dr. Maria Riva at (303) 871-2484. If you have any concerns or complaints about how you were treated during the course of this research, please contact Dr. Dennis Wittmer, Chair, Institutional Review Board for the Protection of Human Subjects, at (303) 871-2431, or write at the University of Denver, Office of Sponsered Programs, 2199 S. University Blvd., Denver, CO 80208-2121.

Your participation in this study is completely voluntary, and you and your adolescent may withdraw your participation at any time. If you choose not to participate or to discontinue your participation, there will be no loss of benefits to you. You and your adolescent may continue to receive services at the outpatient clinic.

I understand that there are two exceptions to the promise of confidentiality. If information is revealed regarding suicide, homicide, or child abuse and neglect, it is required by law that this be reported to the proper authorities. In addition, should any information in this study be subject of a court order or lawful subpoena, the University of Denver may not be able to avoid compliance with the order or subpoena.

I have read and understood the foregoing descriptions of the study on adolescent clients' participation in individual therapy. I have asked for and received a satisfactory explanation of any language that I did not fully understand. I agree to participate in this study, and I understand that I may withdraw my consent at any time. I have received a copy of this consent form. 
What is this study about?

ASSENT FORM (CHILD)

I am being asked if I want to be in this study. The goal of this study is to understand the working relationship between adolescents and their therapists and the adolescents' readiness to change in therapy. The goal is also to understand the relationship between the adolescent client and their therapist as well as the impact of the parent or caregiver on the relationship.

Why are you asking me?

I am being asked to be in the study because I am participating in the Intensive Outpatient Program (IOP) at The Children's Hospital.

What Do I Have to Do or What Will Happen to Me?

If I am in the study, I will:

- Complete three different questionnaires: one about my feelings and behaviors, one about my relationship with my IOP therapists, and one about my relationship with the other IOP group members. Examples of possible questions include:

- "How ready are you to change some of your behavior?"

- "How well do feel your therapist understands your goals?"

- "How well do you feel the group works together?"

- Participate in the study for the same amount of time that I am in the IOP group (five weeks) and spend about 10 minutes before several IOP session completing questionnaires.

- Understand that I can choose not to answer some items on the questionnaire without negative consequences.

- Understand that I can choose to stop participating in the study at any time without negative consequences.

\section{Will this Hurt?}

None of the procedures involved in this study will hurt.

Do I get anything for being in the study?

If I am in the study, I will get a $\$ 15$ gift card to Target.

Can I ask Questions?

I asked any questions I have now about the study. All my questions were answered.

I know that if I have a question later, I can ask and get an answer. If I want to, I can call Jennifer Grote at (720) 335-8244.

\section{Do I Have to Do This?}

I know that I do not have to participate in this study.

I want to be in the study at this time. $\square$ yes $\square$ no

I will get a copy of this form to keep.

Child's Printed Name: Date:

Child's Signature:

I have explained the research at a level that is understandable by the child and believe that the child understands what is expected during this study.

Signature of Person Obtaining

Assent: Date: 


\section{APPENDIX C}

\section{DEMOGRAPHIC QUESTIONNAIRES}




\section{Demographic Questionnaire (Adolescent)}

1. What is your age?:

2. What is your gender? (circle one):
Male
Female
Other

3. With which Racial/Cultural/Ethnic group do you identify? (circle one):

Hispanic/Latino

African American

American Indian

4. What grade are you in?

5. Have you had mental health treatment before? (circle one):

Yes

No

If yes, how long ago?
Asian/Pacific Islander

Caucasian

Other (please specify): 


\section{Demographic Questionnaire (Parent)}

1. What is your gender (circle one):

$\begin{array}{lll}\text { Male } & \text { Female } & \text { Other (please specify): }\end{array}$

2. With which Racial/Cultural/Ethnic group do you identify? (circle one):

Hispanic Asian American

African American Caucasian

Native American Other

3. What is your present relationship status? (circle one):

Single $\quad$ Married Separated

Divorced Widowed

Partnered (living together but not married)

4. Has your adolescent had previous mental health treatment? (circle one):

Yes No

If yes, how long ago? 
APPENDIX D

ASSESSMENT MEASURES 


\section{Working Alliance Inventory (WAI-SR)}

\section{Below is a list of statements about experiences people might have with their}

therapist. Some items refer directly to your therapist with an underlined space

Please mentally insert your therapist's name in the blank. Think about your experiences in therapy and decide which category best describes your own experiences.

1 = Seldom 2 = Sometimes 3 = Fairly Often $\quad 4=$ Very Often $5=$ Always

1. As a result of these sessions I am clearer as to how I might be able to change.

2. What I am doing in therapy gives me new ways of looking at my problem.

3. I believe that my therapist likes me.

4. My therapist and I collaborate on setting goals for my therapy.

5 . My therapist and I respect each other.

6. My therapist and I are working towards goals we agreed upon together.

7. I feel that my therapist appreciates me.

8. My therapist and I agree on what is important for me to work on.

9.

I feel my therapist cares about me even when I do things that he/she does not approve of.

10.

I feel that the things I do in therapy will help me make the changes that I want.

11. My therapist and I have established a good understanding of the kind of changes that would be good for me.

12. I believe the way we are working on my problem is correct. 


\section{URICA (University of Rhode Island Change Assessment)}

\section{Adolescent Version}

Each statement below describes how a person might feel when starting therapy or approaching problems in their lives. Please indicate the extent to which you tend to agree or disagree with each statement. In each case, make your choice in terms of how you feel right now, not what you have felt in the past or how you would like to feel. For all the statements that refer to your "problem", answer in terms of what you write on the "problem" line below. Note that "here" refers to the place of treatment.

There are FIVE possible responses to each of the items in the questionnaire. Please choose the response that best fits how you feel right now.

$1=$ Strongly Disagree

$2=$ Disagree

$$
\begin{aligned}
& 3=\text { Undecided } \quad \begin{array}{l}
4=\text { Agree } \\
5=\text { Strongly Agree }
\end{array}
\end{aligned}
$$

What do you consider to be your "problem" or the reason you are in therapy today? 


\section{For each statement below, place your response on the line to the left of the}

statement.

1 .

2.

3.

4.

5.

6.

7.

8.

9.

10.

11.

12.

13.

14.

15.

16.

17.

18.

19.

20.

\section{1 = Strongly Disagree \\ 4 = Agree \\ $2=$ Disagree \\ 5 = Strongly Agree \\ 3= Undecided}

As far as I'm concerned, I don't have any problems that need changing.

I think I might be ready for some self-improvement.

I am doing something about the problems that had been bothering me.

It might be worthwhile to work on my problem.

I'm not the problem one. It doesn't make much sense for me to be here.

It worries me that I might slip back on a problem I have already changed, so I am here to seek help.

I am finally doing some work on my problem.

I've been thinking that I might want to change something about myself.

I have been successful in working on my problem but I'm not sure I can keep up the effort on my own.

At times my problem is difficult, but I'm working on it.

Being here is pretty much a waste of time for me because the problem doesn't have to do with me.

I'm hoping this place will help me to better understand myself.

I guess I have faults, but there's nothing that I really need to change.

I am really working hard to change.

I have a problem and I really think I should work at it.

I'm not following through with what I had already changed as well as I

had hoped, and I'm here to prevent a relapse of the problem.

Even though I'm not always successful in changing, I'm at least working on my problem.

I thought once I had resolved my problem I would be free of it, but sometimes I still find myself struggling with it.

I wish I had more ideas on how to solve the problem.

I've started working on my problems but I would like help. 


\section{For each statement below, place your response on the line to the left of the}

statement.

$1=$ Strongly Disagree

4 = Agree

21.

22.

.

24.

25.

26.

27.

28.

29.

30.

31.

32. made. them?

$$
\begin{aligned}
& 2=\text { Disagree } \quad 3=\text { Undecided } \\
& \mathbf{5}=\text { Strongly Agree }
\end{aligned}
$$

Maybe this place will be able to help me.

I may need a boost right now to help me keep the changes I've already

I may be part of the problem, but I don't really think I am.

I hope that someone here will have some good advice for me.

Anyone can talk about changing; I'm actually doing something about it.

All this talk about psychology is boring. Why can't people just forget about their problems?

I'm here to prevent myself from having a relapse of my problem.

It is frustrating, but I feel I might be having a recurrence of a problem I thought I had resolved.

I have worries but so does the next guy. Why spend time thinking about

I am actively working on my problem.

I would rather cope with my faults than try to change them.

After all I had done to try to change my problem, every now and again it comes back to haunt me. 


\section{URICA (University of Rhode Island Change Assessment) Parent Version}

Each statement below describes how a person might feel when starting therapy or approaching problems in their lives. Please indicate the extent to which you tend to agree or disagree with each statement. In each case, make your choice in terms of how you feel right now, not what you have felt in the past or how you would like to feel. For all the statements that refer to your "problem", answer in terms of what you write on the "problem" line below. Note that "here" refers to the place of treatment.

There are FIVE possible responses to each of the items in the questionnaire. Please choose the response that best fits how you feel right now.

$1=$ Strongly Disagree

$3=$ Undecided

4= Agree

$2=$ Disagree

5= Strongly Agree

What do you consider to be the "problem" or the reason you have brought your adolescent to therapy today? 


\section{For each statement below, place your response on the line to the left of the statement.}

$\begin{array}{ll}\mathbf{1}=\text { Strongly Disagree } & \mathbf{2}=\text { Disagree } \quad 3=\text { Undecided } \\ \mathbf{4}=\text { Agree } & \mathbf{5}=\text { Strongly Agree }\end{array}$

1 .

2.

3.

4.

5 .

6.

7.

8 .

9.

10 .

11.

12.

13.

14.

15.

16.

17.
As far as I'm concerned, I don't think my adolescent has any problems that need changing.

I think my adolescent might be ready for some self-improvement.

I think my adolescent is doing something about the problems that had been bothering him/her.

It might be worthwhile for my adolescent to work on his/her problem.

My adolescent is not the problem one. It doesn't make much sense for him/her to be here.

It worries me that my adolescent might slip back on a problem he/she has already changed, so we are here to seek help.

My adolescent is finally doing some work on his/her problem.

My adolescent has been thinking that he/she might want to change something about him/herself.

My adolescent has been successful in working on his/her problem but I' $m$ not sure he/she can keep up the effort on my own.

At times his/her problem is difficult, but he/she is working on it.

Being here is pretty much a waste of time for my adolescent because the problem doesn't have to do with him/her.

My adolescent is hoping this place will help him/her to better understand him/herself.

My adolescent guesses he/she has faults, but there's nothing that he/she really needs to change.

My adolescent is really working hard to change.

My adolescent has a problem and he/she really thinks he/she should work at it.

My adolescent is not following through with what he/she had already changed as well as he/she had hoped, and he/she is here to prevent a relapse of the problem.

Even though my adolescent is not always successful in changing, he/she is at least working on his/her problem. 


\section{For each statement below, place your response on the line to the left of the statement.}

$\begin{array}{ll}\mathbf{1}=\text { Strongly Disagree } & \mathbf{2}=\text { Disagree } \quad 3=\text { Undecided } \\ \mathbf{4}=\text { Agree } & \mathbf{5}=\text { Strongly Agree }\end{array}$

18. My adolescent thought once he/she had resolved his/her problem he/she would be free of it, but sometimes he/she still find him/herself struggling with it.

19. My adolescent wishes he/she had more ideas on how to solve the problem.

20 . My adolescent has started working on his/her problems but he/she would like help.

21. Maybe this place will be able to help my adolescent.

22. My adolescent may need a boost right now to help him/her maintain the changes he/she has already made.

23. My adolescent may be part of the problem, but he/she doesn't really think he/she is.

24. My adolescent hopes that someone here will have some good advice for him/her.

25 . Anyone can talk about changing; my adolescent is actually doing something about it.

26. All this talk about psychology is boring. Why can't people just forget about their problems?

27. My adolescent is here to prevent him/herself from having a relapse of his/her problem.

28. ___ It is frustrating, but my adolescent feels he/she might be having a recurrence of a problem he/she thought he/she had resolved.

29. ___ My adolescent has worries but so does the next guy. Why spend time thinking about them?

30. My adolescent is actively working on his/her problem.

31. My adolescent would rather cope with his/her faults than try to change them.

32. After all my adolescent had done to try to change his/her problem, every now and again it comes back to haunt him/her. 
Name: Date:

\section{GROUP QUESTIONNAIRE}

Read each statement carefully and as you answer the questions think of the group as a whole. For each statement fill in the box under the MOST APPROPRIATE heading that best describes the group during the four sessions. Please mark only ONE box for each statement.

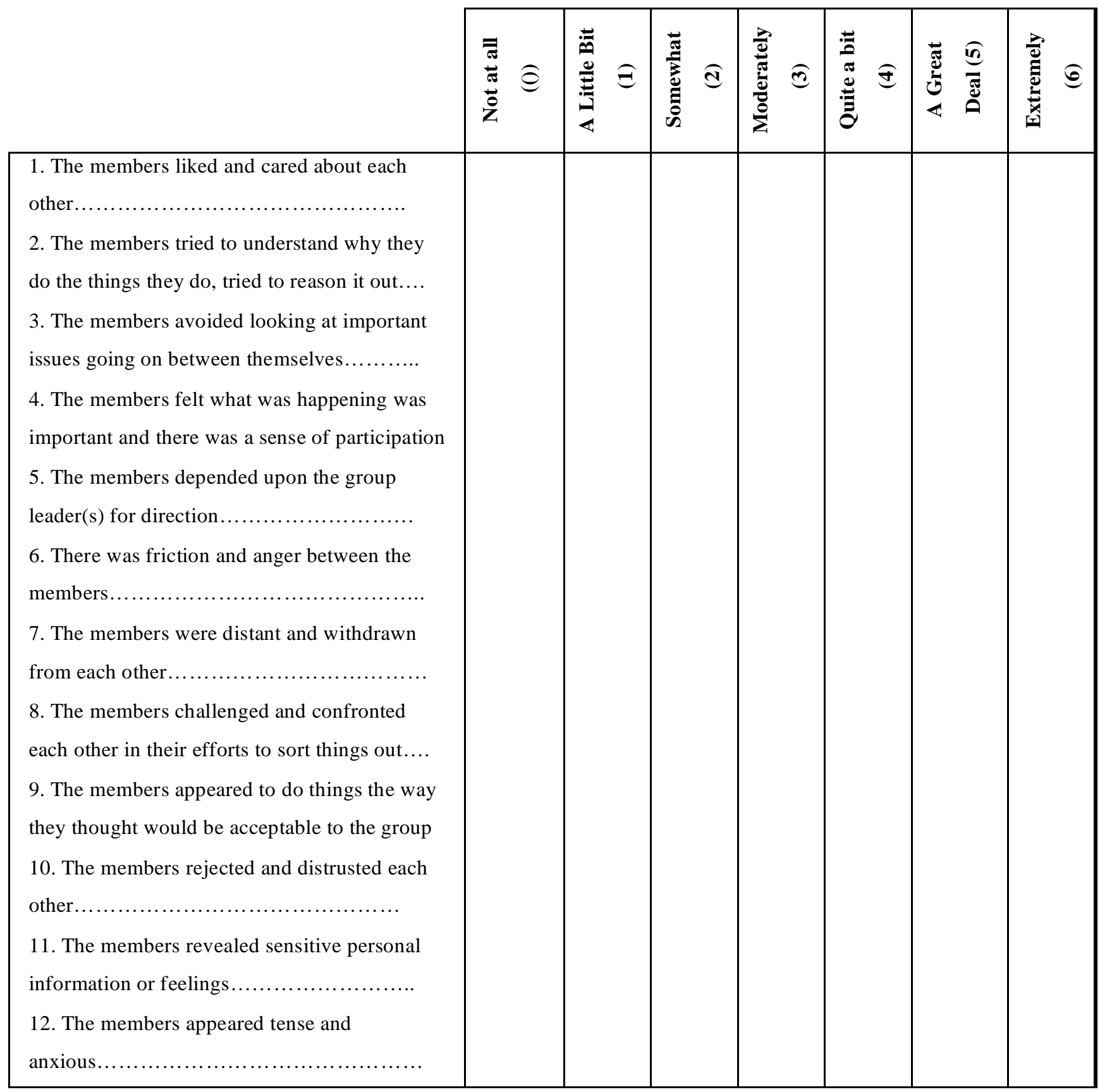




\section{APPENDIX E}

Institutional Review Board Approval Letter 


\section{University of Denver}

Sylk Sotto-Santiago, MBA, MPS

Manager, Regulatory Research Compliance

Tel: 303-871-4052

\section{Certification of Human Subjects Approval}

August 12, 2011

To,

Jennifer Grote, M.Ed

Subject Human Subject Review

TITLE: THE RELATIONSHIP BETWEEN ADOLESCENTS' STAGE OF CHANGE BELIEFS AND THEIR ABILITY TO ESTABLISH A WORKING ALLIANCE IN PSYCHOTHERAPY

IRB\# : 2009-1207

Dear Grote,

The Institutional Review Board for the Protection of Human Subjects has reviewed the above named project. The project has been approved for the procedures and subjects described in the protocol at the 08/09/2011meeting. This approval is effective for twelve months. We will send you a courtesy continuation reminder for this project. However, it is the responsibility of the Principal Investigator to keep track of the expiration date of each protocol. This form must be submitted to the Office of Research and Sponsored Programs if the project continues. This information must be updated on a yearly basis, upon continuation of your IRB approval for as long as the research continues. No human subjects-related work can take place place during an expiration period.

NOTE: Please add the following information to any consent forms, surveys, questionnaires, invitation letters, etc. you will use in your research as follows: This survey (consent, study, etc.) was approved by the University of Denver's Institutional Review Board for the Protection of Human Subjects in Research on 08/09/2011. This information must be updated on a yearly basis, upon continuation of your IRB approval for as long as the research continues. This information will be added by the Research Compliance Office if it does not already appear in the form(s) upon continuation approval.

The Institutional Review Board appreciates your cooperation in protecting subjects and ensuring that each subject gives a meaningful consent to participate in research projects. If you have any questions regarding your obligations under the Assurance, please do not hesitate to contact us.

Sincerely yours,

Paul Olk, PhD

Chair, Institutional Review Board

for the Protection of Human Subjects 
Approval Period:

Review Type:

Funding:

Investigational New Drug:

Investigational Device:

Assurance Number:
8/9/2011 through 8/9/2012

Full Board RENEWAL

SPO:

00004520, 00004520a 